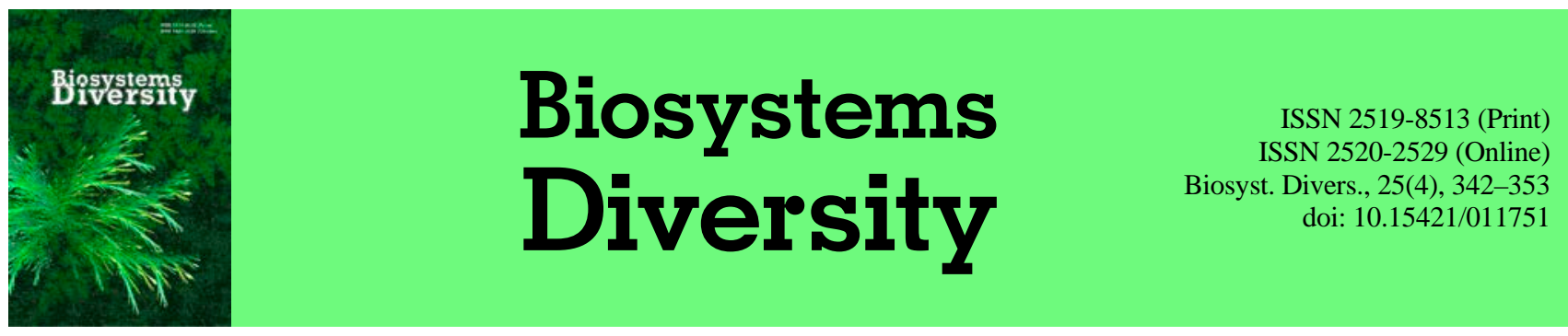

\title{
Parasites of beetles which are pests of grain and products of its processing
}

\author{
V. O. Martynov \\ Oles Honchar Dnipro National University, Dnipro, Ukraine
}

Article info

Received 19.04.2017

Received in revised form 07.05.2017

Accepted 10.05.2017

Oles Honchar Dnipro National University, Gagarin Ave., 72 , Dnipro, 49010, Ukraine. Tel. +38-093-235-39-56. E-mail:

martinov123456789@gmail.com

\author{
Martynov, V. O. (2017). Parasites of beetles which are pests of grain and products of its processing. Biosystems \\ Diversity, 25(4), 342-353. doi:10.15421/011751
}

Crop pests are the cause of economic damage in many developing countries, including Ukraine, where annual loss of crop harvest on average equals 6 million tons, valued at 840 million dollars. Pests consume grain, causing its pollution and creating favorable conditions for development of mold, which significantly decreases the food and seeding properties of grain and products of its processing. This article presents basic data on biological control and its advantages, demonstrates the variety of natural enemies of the pest beetles, which are used in biological control, analyses studies of the biological control of main crop pests and products of its processing belonging to the families Curculionidae and Tenebrionidae, and also the role of competition in biological control. The analysis of studies on the effectiveness of different natural enemies of the main crop pest-beetles shows that the most studied parasites are Sitophilus granarius, S. zeamais, Tribolium confusum, T. castaneum, Oryzaephilus surinamensis, Rhyzopertha dominica, Acanthoscelides obtectus and Callosobruchus maculatus. Natural enemies of the rest of the species are poorly studied, and there is no data on Caulophilus latinasus, Tenebroides mauritanicus, Dermestes lardarius, Ptinus fur and Bruchidius incarnatus. The most commonly used natural enemies are Xylocoris flavipes, Anisopteromalus calandrae, the entomopathogenic fungi Metarhizium anisopliae and Beauveria bassiana, and also nematodes of the Steinernema and Heterorhabditis genera. Despite the broad spectrum of natural enemies of the main pests of the grain supply, it is necessary to further study the parasites of every species of beetle which causes economic damage. Using biological control is the most promising method against pests of crops and products of its processing, which meets the current requirements to the sanitary-ecological condition of agricultural production.

Keywords: biological control; storage; entomopathogenic fungus; Sitophilus; Tribolium; competition

\section{Паразиты жесткокрылых - вредителей зерна и продуктов его переработки}

\author{
В. О. Мартынов
}

\section{Днипровский национальный университет имени Олеся Гончара, Днипро, Украина}

\begin{abstract}
Вредители зерновых наносят значительный экономический ущерб во многих развивающихся странах, в том числе в Украине, где ежегодные потери урожая зерновых составляют в среднем 6 млн тонн стоимостью 840 млн долл. Вредители потребляют зерно в пищу, загрязняют его и создают благоприятные условия для развития плесневых грибов, что значительно снижает пищевые и посевные качества зерна и продуктов его переработки. В статье приведены основные сведения о биологическом контроле и его преимуществах, продемонстрировано разнообразие естественных врагов жесткокрылых-вредителей, применяемых в биологическом контроле, проанализированы исследования биологического контроля основных вредителей зерна и продуктов его переработки из семейств Curculionidae и Tenebrionidae, а также роль конкуренции в биологическом контроле. Обзор исследований эффективности различных естественных врагов основных жесткокрылых - вредителей зерновых показал, что наиболее изучены паразиты Sitophilus granarius, S. zeamais, Tribolium confusum, T. castaneum, Oryzaephilus surinamensis, Rhyzopertha dominica, Acanthoscelides obtectus и Callosobruchus maculatus. Естественные враги остальных видов мало исследованы, а для Caulophilus latinasus, Tenebroides mauritanicus, Dermestes lardarius, Ptinus fur и Bruchidius incarnatus данные отсутствуют. Наиболее широко применяются такие естественные враги, как Хуlocoris flavipes, Anisopteromalus calandrae, энтомопатогенные грибы Metarhizium anisopliae и Beauveria bassiana, а также нематоды из родов Steinernema и Heterorhabditis. Несмотря на широкий спектр естественных врагов основных вредителей запасов, необходимы дальнейшие исследования паразитов каждого вида жесткокрылых, несущих экономический ущерб. Применение биологического контроля является наиболее перспективным методом борьбы с вредителями зерна и продуктов его переработки, отвечающим современным требованиям к санитарно-экологическому состоянию сельскохозяйственной продукции.
\end{abstract}

Ключевые слова: биологический контроль; хранилище; энтомопатогенные организмы; Sitophilus; Tribolium; конкуренция

\section{Актуальность контроля вредителей}

В Украине зарегистрировано 116 видов вредителей хранилищ, которые повреждают зерно и зерновую продукцию (Horshchar et al., 2014). По данным аграрных информационных агентств, урожай зерновых Украины в 2017 году составил 59,9 млн тонн, из которых 43,9 млн тонн выставлены на внешние рынки. В том числе 17,5 млн тонн пшеницы, 5,4 млн тонн ячменя и 20,7 млн тонн кукурузы, стоимостью 2,54, 0,76 и 2,69 млрд долл, соответственно. Ежегодные потери собранного зерна составляют от 5$10 \%$ до $30 \%$ урожая, то есть в среднем 6 млн тонн или 840 млн долл. Поражение зерна насекомыми приводит к снижению его пи- 
щевых и посевных качеств (Berger, 1987; Zakladnoi, 2006). Наиболее распространенными жуками-вредителями являются амбарный Sitophilus granarius Linnaeus, 1758 и рисовый S. oryzae Linnaeus, 1763 долгоносики, малый Tribolium confusum Jacquelin du Val, 1863 и булавоусый T. castaneum Herbst, 1797 мучные хрущаки, суринамский Oryzaephilus surinamensis Linnaeus, 1758 и короткоусый рыжий Cryptolestes ferrugineus Stephens, 1830 мукоеды, зерновой точильщик Rhyzopertha dominica Fabricius, 1792 и гороховая зерновка Bruchus pisorum Linnaeus, 1758 (табл. 1). Реже встречаются кукурузный долгоносик Sitophilus zeamais Motschulsky, 1855, мавританская козявка Tenebroides mauritanicus Linnaeus, 1758, большой мучной хрущак Tenebrio molitor Linnaeus, 1758, ветчинный кожеед Dermestes lardarius Linnaeus, 1758, притворяшка-вор Ptinus fur Linnaeus, 1758, хлебный точильщик Stegobium paniceum
Linnaeus, 1758, зерновки Acanthoscelides obtectus Say, 1831, Bruchus lentis Frolich, 1799, Bruchophagus gibbus Boheman, 1836. Также существует опасность ввоза таких вредителей зерна и зерновой продукции как зерновой Trogoderma granarium Everts, 1898 и разноцветный T. versicolor Creutzer, 1799 кожееды, китайская Callosobruchus chinensis Linnaeus, 1758, четырехпятнистая C. maculatus Fabricius, 1775 и египетская гороховая Bruchidius incarnatus Boheman, 1833 зерновки, амбарный широкохоботный долгоносик Саulophilus latinasus Say и других насекомых Европы, Америки, Азии и Африки, с которыми Украина имеет торговые связи (Seredniak and Fedorenko, 2014). Кроме того, некоторые жесткокрылые-вредители, распространенные в Украине, включены в списки карантинных видов таких стран-импортеров как Индия, Саудовская Аравия, Южная Корея, Марокко и Китай (табл. 2).

Таблица 1

Наиболее распространенные жесткокрылые-вредители*

\begin{tabular}{|c|c|c|c|c|c|c|c|}
\hline Вредитель & Семейство & $\begin{array}{c}\text { Размер } \\
\text { имаго, мм }\end{array}$ & $\begin{array}{l}\text { Оптимальная } \\
\text { температура, } \\
{ }^{\circ} \mathrm{C}\end{array}$ & $\begin{array}{l}\text { Плодо- } \\
\text { витость, } \\
\text { шт. яиц }\end{array}$ & Распространение & Культуры & K \\
\hline $\begin{array}{l}\text { Sitophilus granarius } \\
\text { Linnaeus, } 1758\end{array}$ & Curculionidae & $3,5-4,5$ & 25 & $150-300$ & космополит & $\begin{array}{l}\text { Пшеница, рожь, ячмень, овес, рис, кукуруза, } \\
\text { гречиха, просо, макаронные изделия и мука }\end{array}$ & 1,5 \\
\hline $\begin{array}{l}\text { Sitophilus oryzae } \\
\text { Linnaeus, } 1763\end{array}$ & -“- & $2,5-3,5$ & $28-30$ & $300-576$ & космополит & $\begin{array}{l}\text { Рис, пшеница, рожь, кукуруза, ячмень, мука, } \\
\text { фасоль, просо, масличные и бобовые культуры }\end{array}$ & 1,0 \\
\hline $\begin{array}{l}\text { Sitophilus zeamais } \\
\text { Motschulsky, } 1855\end{array}$ & -“- & $2,5-5,0$ & $25-30$ & $300-400$ & $\begin{array}{c}\text { Умеренно теплые страны } \\
\text { Америки, Европы, Азии } \\
\text { и Африки }\end{array}$ & $\begin{array}{l}\text { Пшшеница, рожь, овес, ячмень, рис, кукуруза, } \\
\text { гречиха, перловая крупа, просо, масличные и } \\
\text { бобовые культуры }\end{array}$ & - \\
\hline $\begin{array}{l}\text { Caulophilus latinasus } \\
\text { (Say, 1831) }\end{array}$ & -“- & $2,5-4,0$ & 25 & $200-300$ & $\begin{array}{c}\text { Северная и Центральная } \\
\text { Америка, Западная } \\
\text { Европа, Марокко }\end{array}$ & $\begin{array}{l}\text { Каштаны, желуди, вяленые плоды инжира, } \\
\text { горох, мука, макароны }\end{array}$ & - \\
\hline $\begin{array}{l}\text { Tribolium confusum } \\
\text { Jacquelin du Val, } 1863\end{array}$ & Tenebrionidae & $3,5-5,0$ & $23-25$ & $\begin{array}{l}300- \\
1000\end{array}$ & космополит & $\begin{array}{l}\text { Мука, крупа, отруби, редко зерно, сушеные } \\
\text { овощи и фрукты }\end{array}$ & 0,4 \\
\hline $\begin{array}{l}\text { Tribolium castaneum } \\
\text { Herbst, } 1797\end{array}$ & -“- & $3,5-5,0$ & $25-30$ & $\begin{array}{l}300- \\
1000\end{array}$ & космополит & Фуражное зерно, крупа, комбикорм, отруби & 0,4 \\
\hline $\begin{array}{l}\text { Tenebrio molitor } \\
\text { Linnaeus, } 1758\end{array}$ & -“- & $13,0-17,0$ & $20-25$ & $270-570$ & космополит & Мука, отруби, пшеница, овес, & 0,4 \\
\hline $\begin{array}{l}\text { Tenebroides mauritanicus } \\
\text { Linnaeus, } 1758\end{array}$ & $-“-$ & $7,0-11,0$ & 27 & $\begin{array}{l}400- \\
1300\end{array}$ & космополит & $\begin{array}{l}\text { Зерно хлебных злаков, мука, крупы, комбикорма, } \\
\text { сухофрукты, кондитерские изделия }\end{array}$ & 1,1 \\
\hline $\begin{array}{l}\text { Oryzaephilus surinamensis } \\
\text { Linnaeus, } 1758\end{array}$ & Silvanidae & $2,0-3,5$ & $25-27$ & $100-600$ & космополит & $\begin{array}{l}\text { Зерно, мука, крупа, кондитерские изделия, } \\
\text { галеты, сушеные фрукты и овощи, семена } \\
\text { масличных культур, орехи }\end{array}$ & 0,3 \\
\hline $\begin{array}{l}\text { Cryptolestes ferrugineus } \\
\text { Stephens, } 1830\end{array}$ & Laemophloeidae & 2,0 & 35 & $200-500$ & космополит & Пшеница, ячмень, рожь, тритикале, овес & - \\
\hline $\begin{array}{l}\text { Rhyzopertha dominica } \\
\text { Fabricius, } 1792\end{array}$ & Bostrichidae & $2,5-3,0$ & $25-30$ & $47-520$ & космополит & $\begin{array}{l}\text { Пшеница, рис, сорго, гречиха, кукуруза, ячмень, } \\
\text { бобы, арахис }\end{array}$ & 1,7 \\
\hline $\begin{array}{l}\text { Dermestes lardarius } \\
\text { Linnaeus, } 1758\end{array}$ & Dermestidae & $7,0-9,0$ & $18-20$ & $102-174$ & Европа и Азия & $\begin{array}{l}\text { Зернобобовые культуры и комбикорма, } \\
\text { макароны, маисовая мука }\end{array}$ & 0,4 \\
\hline $\begin{array}{l}\text { Trogoderma granarium } \\
\text { Everts, } 1898\end{array}$ & -“- & $1,6-3,2$ & $25-40$ & $65-126$ & космополит & $\begin{array}{l}\text { Пшеница, рожь, ячмень, овес, кукуруза, рис, } \\
\text { арахис, семена хлопчатника и льна, мука и } \\
\text { макароны }\end{array}$ & 0,4 \\
\hline $\begin{array}{l}\text { Trogoderma versicolor } \\
\text { Creutzer, } 1799\end{array}$ & -“- & $2,5-6,0$ & $25-30$ & до 30 & $\begin{array}{c}\text { Средняя и } \\
\text { Южная Европа }\end{array}$ & Пшеница, кукуруза, рис, мука & 0,4 \\
\hline $\begin{array}{l}\text { Ptinus fur } \\
\text { Linnaeus, } 1758\end{array}$ & Ptinidae & $3,1-4,3$ & $25-28$ & $60-170$ & космополит & Пшеница, рожь, кукуруза, ячмень, мука, крупа & 0,4 \\
\hline $\begin{array}{l}\text { Stegobium paniceum } \\
\text { Linnaeus, } 1758\end{array}$ & Anobiidae & $1,7-3,7$ & $26-27$ & до 140 & космополит & $\begin{array}{l}\text { Сухари, сушки, галеты, печенье, лекарственное } \\
\text { сырье, сухофрукты, зернопродукты и } \\
\text { комбикорма }\end{array}$ & - \\
\hline $\begin{array}{l}\text { Acanthoscelides obtectus } \\
\text { Say, } 1831\end{array}$ & Chrysomelidae & $2,0-5,0$ & $27-31$ & 20-209 & $\begin{array}{c}\text { Европа, Северная } \\
\text { Африка и Америка }\end{array}$ & Фасоль, бобы, нут, чина, чечевица, горох и соя & - \\
\hline $\begin{array}{l}\text { Bruchus pisorum } \\
\text { Linnaeus, } 1758\end{array}$ & -“- & $4,0-5,0$ & $26-28$ & $70-222$ & космополит & Горох & - \\
\hline $\begin{array}{l}\text { Callosobruchus chinensis } \\
\text { Linnaeus, } 1758\end{array}$ & -“- & 3,0 & 30 & 50-103 & космополит & $\begin{array}{l}\text { Горох, кормовые бобы, чечевица, чина, нут, } \\
\text { фасоль }\end{array}$ & - \\
\hline $\begin{array}{l}\text { Callosobruchus maculatus } \\
\text { Fabricius, } 1775\end{array}$ & -“- & $3,0-3,8$ & $27-30$ & $100-200$ & космополит & Вика, горох, маш, соя, фасоль, чечевица, чина & - \\
\hline $\begin{array}{l}\text { Bruchidius incarnatus } \\
\text { Boheman, } 1833\end{array}$ & -“- & $3,0-3,5$ & $27-30$ & 10 & $\begin{array}{c}\text { Испания, Португалия, } \\
\text { Франция, Египет, } \\
\text { Канарские острова, Тунис }\end{array}$ & $\begin{array}{l}\text { Вика, горох, каянус, нут, чечевица } \\
\text { с }\end{array}$ & - \\
\hline
\end{tabular}

Примечания: *-по данным Sokolov (2004); ** - по данным Ganiev et al. (2009) и Feydengold et al. (2007); «-»-данные отсутствуют; К-коэффициент вредоносности.

Вредители хранилищ потребляют зерно в пищу и загрязняют его экскрементами, сброшенной кутикулой и мертвыми особями. Жизнедеятельность насекомых способствует уплотнению и склеиванию зерна, повышению температуры и влажности в местах их локализации, что создает благоприятные условия для развития плесневых грибов в поврежденном зерне. Употребление такого зерна в пищу может вызвать отравление у человека и животных токсичными и канцерогенными веществами, продуцируемыми плесенью. Кроме того, поврежденное зерно непригодно для получения высококачественной продукции и имеет низкую стоимость 
(Christensen, 1972; Bashynska, 2004). При наличии в зерне или зерновой продукции даже незначительного количества вредителей необходимо немедленно прибегать к мерам по их уничтожению. На сегодня в Украине ведущую роль в борьбе с вредителями играют химические методы, включающие влажную и аэрозольную дезинсекцию, фумигацию и использование ядовитых приманок (Horshchar et al., 2014). Согласно современным требованиям касательно санитарно-экологического состояния сельскохозяйственной продукции, необходимо снижение пестицидной нагрузки на окружающую среду и постепенное замещение химических методов защиты альтернативными. Наиболее благоприятными и перспективными являются биологические методы контроля вредителей.

\section{Таблица 2}

Карантинные вредители

стран-импортеров основных зерновых культур

\begin{tabular}{|c|c|c|c|c|}
\hline $\begin{array}{l}\text { Страна- } \\
\text { импортер }\end{array}$ & $\begin{array}{l}\text { Пшеница, } \\
\text { млн тонн }\end{array}$ & $\begin{array}{l}\text { Ячмень, } \\
\text { млн тонн }\end{array}$ & $\begin{array}{l}\text { Кукуруза, } \\
\text { млн тонн }\end{array}$ & $\begin{array}{c}\text { Карантинные } \\
\text { вредители* }\end{array}$ \\
\hline Индия & 2,92 & - & - & $\begin{array}{c}\text { Acanthoscelides obtectus, } \\
\text { Cryptolestes ferrugineus, } \\
\text { Sitophilus granaries, }\end{array}$ \\
\hline
\end{tabular}

$\begin{array}{lc}\text { Египет } & 2,50 \\ \text { Бангладеш } & 1,71 \\ \text { Саудовская } & - \\ \text { Аравия } & \\ \text { Индонезия } & 1,61 \\ \text { Таиланд } & 1,59 \\ \text { Южная Корея } & 1,06\end{array}$

$\begin{array}{cc}- & 3,37 \\ - & - \\ 2,30 & - \\ - & - \\ - & - \\ - & 0,68\end{array}$
Sitophilus zeamais

\begin{tabular}{lcccc} 
Марокко & & & & $\begin{array}{c}\text { Trogoderma granarium } \\
\text { Trogoderma granarium }\end{array}$ \\
Филиппины & 0,98 & 0,14 & - & - \\
Тунис & 0,68 & - & - & - \\
Израиль & 0,64 & 0,18 & 0,91 & - \\
Ливия & 0,49 & 0,20 & 0,97 & - \\
Китай & - & 0,96 & - & Acanthoscelides obtectus, \\
& - & 0,30 & 1,36 & Bruchus pisorum, \\
& & & & Trogoderma versicolor, \\
Алжир & & & & Trogoderma granarium \\
Иордания & - & 0,22 & - & - \\
Турция & - & 0,22 & - & - \\
Испания & - & 0,13 & - & - \\
Нидерланды & - & 0,12 & 2,42 & - \\
Иран & - & - & 2,44 & - \\
Италия & - & - & 2,23 & - \\
Португалия & - & - & 1,57 & - \\
\hline
\end{tabular}

Примечания: * - согласно перечням карантинных вредителей для каждой страны; «-»-виды, зарегистрированные в Украине, не являются карантинными.

\section{Биологический контроль как метод борьбы с вредителями}

В борьбе с вредителями биологический контроль направлен на снижение численности популяции вредителя под воздействием хищников, паразитов или патогенов. Биологический контроль является частью естественного контроля, но подразумевает манипулирование населением естественных врагов человеком и может применяться для любого вредителя. Биологический контроль можно определить как «изучение и использование хищников, паразитов и патогенов для регулирования плотности вредителей» (DeBach, 1964). В природных условиях эффект биологического контроля на разнообразие местных видов может быть как положительным, так и отрицательным. Основной проблемой является влияние естественных врагов целевого вредителя на другие виды насекомых. Поэтому при введении вида-регулятора основной задачей является установка специфичности к хозяину. Потенциальный энтомофаг, применяемый в биологическом контроле, должен пройти обширное тестирование и карантин перед выпуском в среду обитания вредителя, так как если он поражает широкий диа- пазон хозяев, возможны масштабные изменения биоразнообразия. Динамика популяций инвазивных насекомых демонстрирует картину взлета и падений, где численность и ущерб достигают максимальных значений вскоре после инвазии, а затем популяция начинает разрушаться. Одной из причин распада является деятельность местных врагов. Kenis and Branco (2017) предполагают, что местные естественные враги будут воздействовать на инвазивных насекомых, если они принадлежат к видам, которых обычно поедают полифаги или которые экологически и таксономически тесно связаны с захватчиком. Местные естественные враги со временем атакуют инвазивных насекомых и могут частично или полностью контролировать вредителя, однако результаты весьма непредсказуемы и в большинстве случаев недостаточны для обеспечения удовлетворительного контроля.

В условиях хранилищ проблема влияния естественных врагов на нецелевые виды отсутствует, так как их нет. Динамика популяций вредителей имеет постоянный характер, что связано с благоприятными условиями, избытком пищи и отсутствием хищников. Колебания могут возникать при внутри- и межвидовой конкуренции, в случае заражения зерна несколькими видами вредителей. Биологический контроль является одним из немногих методов борьбы с вредителями, имеющим постоянный характер и не требующим никаких действий после выпуска и распространения естественных врагов. В долгосрочной перспективе биологический контроль имеет множество преимуществ по сравнению с другими стратегиями борьбы, особенно с химическими методами. К ним относятся безопасность для окружающей среды, отсутствие остатков, экономичность, простота в применении, продолжительность действия, отсутствие выработки устойчивости вредителей. К недостаткам биологического контроля можно отнести возможные сложности доставки, хранения и применения естественных врагов; дороговизна по сравнению с другими методами, связанная с предварительными исследованиями; невысокая скорость контроля из-за отставания между приростом численности популяции вредителей и приростом вида-регулятора (Kwenti, 2017).

Расчет выгод биологического контроля затрудняется из-за срочности реализации, сложности методики, отсутствия финансирования и приоритета пост-релиз мониторинга. Однако в ряде работ приводятся данные, иллюстрирующие несомненное преимущество биологического контроля с экономической точки зрения. Cock et al. (2015) приводят данные, что проекты биологического контроля мучнистого червеца Phenacoccus manihoti Matile-Ferrero, 1977 и маргародиды Drosicha mangiferae Stebbins, 1903 в Африке имеют оценочные коэффициенты соотношения затрат и выгоды $1: 738$ и $1: 808$ соответственно. Подобные результаты приводятся в работах Hill and Greathead (2000), Gutierrez et al. (1999), Dahlsten et al. (1998) и других. Но необходимо много времени для разработки технологий контроля и последующего мониторинга исследуемой экосистемы.

На сегодняшний день исследовано более 2000 естественных врагов и энтомопатогенов для борьбы с насекомыми-вредителями по всему миру (Cock et al., 2016). Методы биологического контроля продолжают активно развиваться, расширяется использование естественных врагов, выявляются новые виды-регуляторы численности насекомых и модифицируются старые, разрабатываются новые методики с применением био- и нанотехнологии для более эффективной борьбы с вредителями (Goswami et al., 2010; Ma et al., 2015).

\section{Естественные враги насекомых-вредителей}

Клещи. Клещи семейства Acarophenacidae - паразиты яиц различных насекомых-вредителей. Данные о хозяевах и распространении 11 видов рода Acarophenax приводятся в работе Rahiminejad and Hajiqanbar (2015). Acarophenax lacunatus Cross \& Krantz поражает C. ferrugineus, $R$. dominica и T. castaneum, однако не может паразитировать на O. surinamensis. В исследовании Oliveira et al. (2003) клещ вызывал значительное снижение на $61 \%$ численности популяций $R$. dominica и на $53 \%$ - популяций $T$. castaneum. A. lacunatus смог значительно уменьшить мгновенную 
скорость роста C. ferrugineus, $R$. dominica и T. castaneum. Диапазон хозяев A. lacunatus не столь широк, как среди других паразитических клещей - естественных врагов насекомых-вредителей. Например, Pyemotes tritici LaGrèze-Fossat and Montagné, 1851 атакует Plodia interpunctella Hübner, 1813 и Cadra cautella Walker, 1863, Lasioderma serricorne Fabricius, 1792 и даже O. surinamensis (Bruce and LeCato, 1979). При отсутствии основного хозяина C. cautella, Blattisocius tarsalis Berlese, 1918 также способен питаться T. castaneum. Способность клещей успешно паразитировать на нескольких видах - благоприятная характеристика для его потенциального использования в биологическом контроле вредителей зерновых культур (Oliveira et al., 2003). На сегодня эффективность использования клещей для борьбы с основными жесткокрылыми вредителями зерновых исследована только для T. castaneum, O. surinamensis, C. ferrugineus и $R$. dominica (табл. 3).
Насекомые. Для борьбы с насекомыми-вредителями широко используются такие хищники как Xylocoris flavipes Reuter, 1884 и несколько других клопов подсемейства Lyctocorinae (Reichmuth, 2000). Эти клопы являются перспективными регуляторами численности насекомых из отрядов Coleoptera и Lepidoptera в складских помещениях. Они обладают высокой способностью к повышению численности даже при недостатке добычи. Однако X. flavipes не эффективен против долгоносиков, которые скрываются в зерне (Arbogast, 1975) и карапузика Teretriosoma nigrescens Lewis (Pöschko et al., 1992; Richter et al., 1997). Эффективность X. flavipes в биологическом контроле исследована для S. granarius, S. zeamais, T. confusum, T. castaneum, O. surinamensis, C. ferrugineus, S. paniceum и A. obtectus. Schmale et al. (2001) оценили потенциал паразитоидов зерновки A. obtectus. Наиболее перспективным паразитоидом для контроля A. obtectus является Dinarmus basalis Rond. с продолжительной репродукцией и многочисленным потомством.

Таблица 3

Состояние исследования эффективности естественных врагов для контроля основных жесткокрылых-вредителей зерна

\begin{tabular}{|c|c|c|c|c|c|c|c|c|c|c|c|c|c|c|c|c|c|c|c|c|c|}
\hline \multirow[b]{2}{*}{ Естественные враги } & \multicolumn{21}{|c|}{ Вредители } \\
\hline & 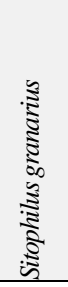 & 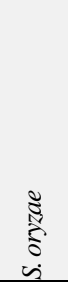 & 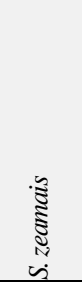 & 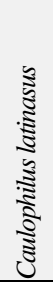 & 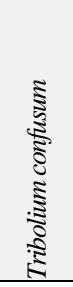 & 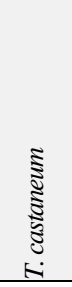 & 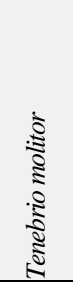 & 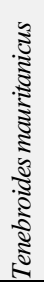 & 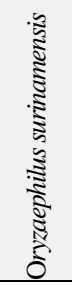 & 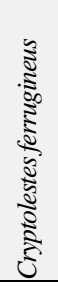 & 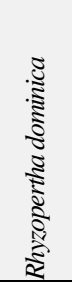 & 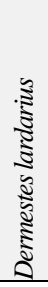 & 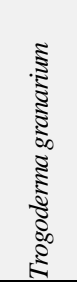 & 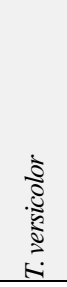 & $\frac{\mathfrak{z}}{\mathfrak{\Xi}}$ & 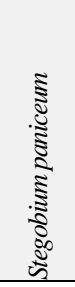 & 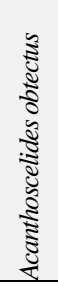 & 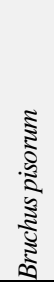 & 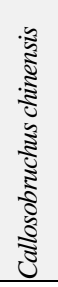 & 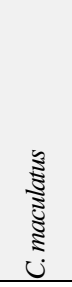 & 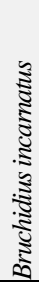 \\
\hline $\begin{array}{l}\text { Acarophenax lacunatus } \\
\text { Cross \& Krantz }\end{array}$ & - & - & - & - & - & $+^{1}$ & - & - & -1 & $+^{1}$ & $++^{1,2}$ & - & - & - & - & - & - & - & - & - & - \\
\hline $\begin{array}{l}\text { Pyemotes tritici LaGrèze- } \\
\text { Fossat and Montagné, } 1851\end{array}$ & - & - & - & - & - & - & - & - & $t^{3}$ & - & - & - & - & - & - & - & - & - & - & $+^{4}$ & - \\
\hline $\begin{array}{l}\text { Blattisocius tarsalis } \\
\text { Berlese, } 1918\end{array}$ & - & -6 & - & - & - & $++^{5,6}$ & - & - & - & $++^{6}$ & -6 & - & - & - & - & - & $++^{6}$ & - & - & - & - \\
\hline $\begin{array}{l}\text { Xylocoris flavipes } \\
\text { Reuter, } 1884\end{array}$ & $+^{10}$ & - & $+^{10}$ & - & $++^{9,10}$ & $+7,8,10$ & - & - & $+^{7}$ & $++^{10}$ & - & - & - & - & - & $+9,10$ & $++^{10}$ & - & - & - & - \\
\hline $\begin{array}{l}\text { Trichogramma evanescens } \\
\text { Westwood, } 1833\end{array}$ & - & - & - & - & - & - & -11 & - & - & - & - & $++^{10}$ & - & - & - & - & $++^{10}$ & -11 & - & - & - \\
\hline $\begin{array}{l}\text { Anisopteromalus calandrae } \\
\text { Howard, } 1881\end{array}$ & $+{ }^{10,16}$ & $++^{12,16}$ & $+^{10,12,16}$ & - & - & $++^{16}$ & - & - & $++^{16}$ & & $+\stackrel{10,12}{16}$ & - & - & - & - & $++^{10,16}$ & $++^{10}$ & - & $++^{16}$ & $+{ }^{13,16}$ & - \\
\hline $\begin{array}{l}\text { Holepyris sylvanidis } \\
\text { (Brethes, 1913) }\end{array}$ & - & - & - & - & $+^{10}$ & $++^{10}$ & - & - & - & $+{ }^{10}$ & - & - & - & - & - & - & - & - & - & - & - \\
\hline $\begin{array}{l}\text { Laelius pedatus } \\
\text { Say, } 1836\end{array}$ & - & - & - & - & - & - & - & - & - & - & - & - & $++^{14,15}$ & $++^{14,15}$ & - & - & - & - & - & - & - \\
\hline $\begin{array}{l}\text { Dinarmus basalis } \\
\text { (Rondani, 1877) }\end{array}$ & - & - & - & - & - & - & - & - & - & - & - & - & $+{ }^{16}$ & $+{ }^{16}$ & - & - & $++^{16}$ & - & $+{ }^{16}$ & $++^{16}$ & - \\
\hline $\begin{array}{l}\text { Amphibolus venator } \\
\text { (Klug, 1830) }\end{array}$ & - & - & $++^{18}$ & - & $+{ }^{17}$ & $+^{17}$ & - & - & - & - & - & - & $+{ }^{17}$ & - & - & - & - & - & - & - & - \\
\hline $\begin{array}{l}\text { Peregrinator biannulipes Mon- } \\
\text { trouzier and Signoret, } 1861\end{array}$ & $+^{20}$ & - & - & - & - & $++^{19}$ & $++^{19}$ & - & $++^{19}$ & $+{ }^{19}$ & $++^{19}$ & - & - & - & - & $+{ }^{19}$ & - & - & - & - & - \\
\hline $\begin{array}{l}\text { Theocolax elegans } \\
\text { Westwood, } 1874\end{array}$ & $+^{16}$ & $+{ }^{16}$ & $+{ }^{12,16}$ & - & - & $+^{21}$ & - & - & - & $+^{21}$ & $++^{12,16}$ & - & - & - & - & - & - & - & $+{ }^{16}$ & $+{ }^{16}$ & - \\
\hline $\begin{array}{l}\text { Metarhizium anisopliae (Met- } \\
\text { chnikoff, 1879) Sorokin, } 1883\end{array}$ & - & $+^{24}$ & - & - & $++^{24}$ & $+23,28$ & $++^{27}$ & - & $++^{23,28}$ & - & $+{ }^{24,28}$ & - & $++^{22,30}$ & $+^{30}$ & - & - & - & - & - & $++^{24}$ & - \\
\hline $\begin{array}{l}\text { Beauveria bassiana (Bals.- } \\
\text { Criv., 1836) Vuill., } 1912\end{array}$ & - & $+^{25}$ & $+^{26}$ & - & - & $++^{25,28}$ & - & - & $+{ }^{28,29}$ & $++^{29}$ & $+{ }^{28,29}$ & - & $+^{30}$ & $+^{30}$ & - & - & $+^{25}$ & - & - & $++^{24}$ & - \\
\hline $\begin{array}{l}\text { Steinernema carpocapsae } \\
\text { (Weiser, 1955) }\end{array}$ & $+^{31}$ & $++^{33,35}$ & $+^{35}$ & - & $+^{37}$ & $+^{33}$ & $++^{33,35}$ & - & $t^{31}$ & - & $+{ }^{33}$ & - & - & - & - & - & $+^{35}$ & - & - & $++^{40}$ & - \\
\hline $\begin{array}{l}\text { Steinernema riobraus Caba- } \\
\text { nillas, Poinar \&Raulston, } 1994\end{array}$ & - & $+^{35}$ & $+^{35}$ & - & - & - & $+^{35}$ & - & - & - & - & - & - & - & - & - & $+^{35}$ & - & - & - & - \\
\hline $\begin{array}{l}\text { Steinernema feltiae } \\
\text { (Filipjev, 1934) }\end{array}$ & $t^{31}$ & $++^{32,33}$ & - & - & $++^{34,37}$ & $t^{33}$ & $+^{33}$ & - & $+^{31}$ & - & $+^{33}$ & - & - & - & - & - & - & - & $+^{36}$ & - & - \\
\hline $\begin{array}{l}\text { Heterorhabditis bacteriophora } \\
\text { (Poinar, 1975) }\end{array}$ & $+^{31}$ & $+^{35}$ & $+^{35}$ & - & $t^{37}$ & - & $t^{35}$ & - & $+^{31}$ & - & $++^{39}$ & - & - & - & - & - & $t^{35}$ & - & $+^{36}$ & - & - \\
\hline $\begin{array}{l}\text { Heterorhabditis megidis } \\
\text { Poinar, Jackson \& Klein, } 1987\end{array}$ & $++^{31}$ & - & - & - & $++^{37}$ & $++^{38}$ & - & - & $++^{31}$ & - & - & - & - & - & - & - & - & - & - & - & - \\
\hline
\end{tabular}

Примечания: «+» - паразит эффективен в борьбе с вредителем; «-» - паразит не влияет на вредителя; «-» - данные отсутствуют; ${ }^{1}-$ Oliveira et al. (2003); ${ }^{2}$. Gonçalves et al. (2004); ${ }^{3}$ - Bruce and LeCato (1979); ${ }^{4}$ - Romero Ferreira de Oliveira et al. (2010); ${ }^{5}$ - Haines (1981); ${ }^{6}$ - Riudavets et al. (2002); ${ }^{7}$ - LeCato and Davis (1973); ${ }^{8}$ - Russo et al. (2004); ${ }^{9}$ - Awadallah et al. (1986); ${ }^{10}$ - Reichmuth (2000); ${ }^{11}$ - Salt (1938); ${ }^{12}$ - Flinn and Schöller (2012); ${ }^{13}$ - Heong (1981); ${ }^{14}$ - Klein and Beckage (1990); ${ }^{15}$ - Al-Kirshi (1998); ${ }^{16}$ - Binoy (2015); ${ }^{17}$ - Nishi et al. (2004); ${ }^{18}$ - Murata et al. (2016); ${ }^{19}$ - Kang et al. (1984); ${ }^{20}-$ Upadhyay and Ahmad (2011); ${ }^{21}$ Flinn et al. (2006); ${ }^{22}$ - Khashaveh et al. (2011); ${ }^{23}$ - Khashaveh and Chelav (2013), Mahdneshin (2011); ${ }^{24}-$ Kavallieratos et al. (2006); ${ }^{25}-$ Padin et al(2002); ${ }^{26}$ - Meikle et al. (2001); ${ }^{27}$ - Shah et al. (2005); ${ }^{28}$ - Shafighi et al. (2014); ${ }^{29}$ - Lord (2001); ${ }^{30}$ - Draganova and Staneva (2016); ${ }^{31}$ - Trdan et al. (2006); ${ }^{32}-$ Laznik et al. (2010); ${ }^{33}$ Ramos-Rodriguez et al. (2006); ${ }^{34}$ - Athanassiou et al. (2008); ${ }^{35}$ - De Carvalho Barbosa Negrisoli et al. (2013); ${ }^{36}$ - Fayyaz and Javed (2009); ${ }^{37}$ - Rumbos and Athanassiou (2012); ${ }^{38}$ - Shrestha and Kim (2010); ${ }^{39}$ - Athanassiou et al. (2010); ${ }^{40}$ - EI-Orabi et al. (2007). 
A. calandrae оказался непригодным в качестве контрольного агента против этого хозяина. Heterospilus prosopidis Viereck, 1910 имел более короткий период яйцекладки, чем D. basalis, что привело к более низкой продолжительности жизни потомства. Применение D. basalis исследовано для борьбы с T. granarium, T. versicolor, A. obtectus, C. chinensis и C. maculatus.

Amphibolus venator Klug является хищником многих насекомых-вредителей хранилищ. Он охотится на S. zeamais, T. granarium, T. castaneum, Corcyra cephalonica Stainton, 1866, Latheticus oryzae Waterhouse, 1880 и Alphitobius diaperinus Panzer, 1797 (Pingale, 1954; Haines, 1991). Pingale (1954) указывал, что A. venator является эффективным регулятором численности C. cautella и A. diaperinus. В исследовании Nishi et al. (2004) сообщается, что A. venator охотится на личинок, куколок и взрослых особей T. confusum, отдавая предпочтение первым. Хищничество более выражено при $30^{\circ} \mathrm{C}$, чем при $25^{\circ} \mathrm{C}$, так как оптимальная температура для размножения и развития $A$. venator составляет $30-32^{\circ} \mathrm{C}$. Температуры ниже $25^{\circ} \mathrm{C}$ непригодны для развития нимф (Nishi and Takahashi, 2002). Самки имеют тенденцию потреблять больше добычи, чем самцы, поскольку им необходимо производить яйца.

Другой хищник, Peregrinator biannulipes Montrouzier and Signoret, 1861 хорошо известен как естественный враг насекомых вредителей хранилищ. Он охотится на молей и жуков, среди которых T. castaneum, T. confusum, Stegobium paniceum Linnaeus, 1758 и L. serricorne (Tawfik et al., 1983; Awadallah and Afifi, 1990). Эффективность $P$. biannulipes также исследована для борьбы с S. granarius, $T$. molitor, $O$. surinamensis, $C$. ferrugineus и $R$. dominica. Laelius pedatus Say, 1836 - естественный враг кожееда Anthrenus verbasci Linnaeus, 1767 и нескольких видов Trogoderma (Klein and Beckage, 1990; Al-Kirshi, 1998).

Одним из наиболее эффективных паразитоидов является птеромалида T. elegans, атакующая первичных вредителей зерна, таких как Sitophilus spp., $R$. dominica, S. paniceum, C. maculatus, $C$. chinensis и зерновую моль Sitotroga cerealella Olivier, 1789 (Burks, 1979; Flinn et al., 1996; Flinn, 1998; Flinn and Hagstrum, 2001). Однако T. elegans не паразитирует на вторичных вредителях, включая Tribolium spp. и C. ferrugineus, незрелые стадии которых развиваются за пределами зернового ядра. В исследовании Flinn et al. (2006) обработка паразитоидом обеспечивала значительное снижение численности популяций S. zeamais, $T$. castaneum и $C$. ferrugineus на $78 \%, 94 \%$ и $70 \%$, соответственно по сравнению с контрольной группой.

Эффективность A. calandrae исследована для контроля S. granarius, S. oryzae, S. zeamais, T. castaneum, O. surinamensis, S. paniceum, A. obtectus, C. chinensis и C. maculatus. Menon et al., (2002) изучали влияние A. calandrae, паразитирующего на $R$. dominica в пшенице, при различном диапазоне температур и плотности хозяина. Эффективность паразитоида возрастает с повышением температуры. Максимальное количество пораженных личинок наблюдалось при $35^{\circ} \mathrm{C}$ и составляло 15 особей за 24 часа. При $20^{\circ} \mathrm{C}$ этот показатель сокращался до двух личинок. Интересно отметить, что при $38^{\circ} \mathrm{C}$ смертность ос значительно возрастает при низкой плотности хозяина, однако если плотность хозяина высокая, хищники сохраняются, что связанно с восполнением потерянной жидкости с пищей.

Взрослые самки A. calandrae могут выжить до 75 дней в присутствии хозяев и при наличии целлюлозы в качестве дополнительного источника пищи (Chatterji, 1955). Самки паразитоида выживают до 40 дней при условии непрерывного снабжения хозяевами. Паразитоид является полифагом и способен выживать на различных хозяевах, таких как S. oryzae, S. zeamais (Williams and Floyd, 1971; Press et al., 1984). Способность A. calandrae находить и паразитировать на $R$. dominica в широком диапазоне температур делает их хорошими кандидатами для биологического контроля вредителей зернохранилищ в областях с частыми колебаниями температуры.

Грибы. Наиболее распространенными видами энтомопатогенных грибов являются гифомицеты-космополиты Metarhizium anisopliae (Metchnikoff, 1879) Sorokin, 1883 и Beauveria bassiana
(Bals.-Criv., 1836) Vuill., 1912. При благоприятных условиях они нередко вызывают естественные вспышки, поражая широкий круг насекомых и паукообразных. В исследованиях по развитию этих грибов предприняты значительные усилия для применения их в качестве контрольных агентов в сельском и лесном хозяйстве умеренной климатической зоны. Благодаря длительному выживанию в почве эти грибы обеспечивают долгосрочный контроль, уничтожая личинок и куколок насекомых. Они эффективны в борьбе с москитами, заражая их на ранних этапах жизни и убивая через 3-14 дней (Quesada-Moraga et al., 2006; Leger, 2008; Ebrahim, 2015). На основе B. bassiana доступно множество продуктов: Mycotrol ESO and WPO (BioWorks Inc.), Naturalis L (Troy BioSciences, Inc.) и Biosect $^{\circledR}$ (KZ Chemicals).

Эффективность использования энтомопатогенных грибов исследована для многих жесткокрылых - вредителей зерна, таких как S. oryzae, S. zeamais, T. confusum, T. castaneum, T. molitor, $O$. surinamensis, C. ferrugineus, $R$. dominica, T. granarium, T. versicolor, A. obtectus и C. maculatus.

Adane et al. (1996) исследовали несколько изолятов B. bassiana против взрослых особей S. zeaтais. Вирулентность исследуемых изолятов варьировала, смертность $S$. zeamais составляла $37-100 \%$. Кроме того, установлено среднее летальное время для различных изолятов, минимальный показатель которого составляет три дня.

Lord (2001) изучал влияние B. bassiana на долгоносика O. surinamensis и его контрольного агента C. tarsalis. Обработка личинок долгоносика грибом приводит к тому, что все потомство осы на зараженных хозяевах погибнет через два дня после кладки и яйцекладки прекратятся на четвертые сутки после обработки. Уменьшение откладывания яиц связано со смертью хозяина. Несмотря на восприимчивость к грибу, частота посещения хранилища C. tarsalis не меняется, даже при содержании конидий 500 мг/кг пшеницы, определяемом визуально. Осы не способны обнаружить пораженных хозяев и избежать смертельной концентрации конидий на поверхности зерна. Воздействие B. bassiana с концентрацией 100 мг/кг пшеницы на взрослых самок $C$. tarsalis в течении трех часов привело к 52,7\% смертности. Самцы C. tarsalis менее восприимчивы к грибу.

Khashaveh et al. (2011) изучали патогенность M. anisopliae для T. granarium. В эксперименте использовалась серия суспензий от $1 \cdot 10^{5}$ до $1 \cdot 10^{9}$ конидий/мл. Все изоляты патогенны для взрослых и личинок, смертность повышена с увеличением концентрации конидий и значительно варьирует в зависимости от изолята. Общая смертность через 10 дней составила 21-84\%, однако один из изолятов продемонстрировал $100 \%$ смертности при максимальной концентрации. M. anisopliae является приемлемым агентом биологического контроля T. granarium, однако необходимы дальнейшие эксперименты для повышения его эффективности.

Нематоды. Энтомопатогенные нематоды - еще одни паразиты, которые могут быть использованы в сочетании с паразитоидами и другими стратегиями биологического контроля. Они успешно использованы для управления большим количеством насекомых-вредителей (Schroer et al., 2005; Canhilal and Carner, 2006; Mwaitulo et al., 2011; Kega et al., 2013; Dito et al., 2016; Noosidum et al., 2016). Энтомопатогенные нематоды являются безопасным агентом борьбы, не несущим вреда человеку, позвоночным животным и растениям.

Эффективные агенты контроля для широкого спектра вредителей - нематоды родов Steinernema и Heterorhabditis. Они проникают в организм хозяина с пищей, через покровы и дыхальца. Нематоды содержат специфические симбиотические бактерии, которые приводят к гибели хозяина и способствуют его разложению, предоставляя пищу нематодам (Grewal et al., 2005). Для Steinernema характерно присутствие бактерий Xenorhabdus spp., для Heterorhabditis - Photorhabdus spp. (Khater, 2012). Энтомопатогенные нематоды обычно вызывают высокий уровень смертности испытуемых насекомых. По данным Caroli et al. (1996), Steinernema sp. приводили к смертности $20-100 \%$ для T. molitor. Скорость проникновения нематод в T. molitor значительно варьировала, в зависимости от вида. Наибольшее значение отмечено для S. glaseri и 
S. feltiae, самые низкие - для Heterorhabditis sp. (Caroli et al., 1996). Энтомопатогенные нематоды широко коммерчески используются для борьбы с насекомыми. Исследовано их применение для контроля S. granarius, S. oryzae, S. zeamais, T. confusum, T. castaneum, T. molitor, O. surinamensis, C. ferrugineus, R. dominica, A. obtectus, C. chinensis и C. maculatus. На сегодня доступны S. carpocapsae, S. riobraus, S. feltiae, S. glaseri, $H$. bacteriophora, $H$. megidis и H. marelatus, а также нематодные продукты Spear ${ }^{\circledR}$ и Saf T-Shield ${ }^{\circledR}$ (Kaya and Koppenhöfer, 1996).

Ramos-Rodriguez et al. (2007) изучали эффективность энтомопатогенной нематоды $S$. riobrave против вредителей хранилищ T. castaneum и P. interunctella. Применение патогена снижало выживаемость всех стадий T. castaneum с 77,9\% в контроле до $27,4 \%$. Температура $\left(25\right.$ и $\left.30{ }^{\circ} \mathrm{C}\right)$ и относительная влажность (40-100\%) не оказали существенного влияния на эффективность S. riobrave в этом эксперименте. При использовании агента в полевых условиях на $T$. castaneum и $P$. interunctella, общая выживаемость составляла $42 \%$ и $27 \%$ соответственно, по сравнению с контролем. Личиночные стадии наиболее восприимчивы к S. riobrave для обоих видов насекомых, смертность которых составляла 99\% и $80 \%$ для $P$. interunctella и $T$. castaneum соответственно. S. riobrave является перспективным агентом биологического контроля для насекомых вредителей зерновых хранилищ.

Следует отметить, что применение естественных врагов в биологическом контроле таких вредителей как C. latinasus, T. mauritanicus, D. lardarius, $P$. fur и B. incarnatus практически не исследовано.

\section{Биологический контроль основных вредителей хранилищ}

Curculionidae. Исследование биологического контроля S. oryzaе проводили Riudavets and Lucas (2000). Естественные враги вредителя - распространенные паразитические осы A. calandrae и L. distinguendus, поражающие личинок долгоносика. Их потенциал продемонстрирован для $S$. zeamais и $S$. оryzaе в ряде работ (Arbogast and Mullen, 1990; Wen et al., 1994; Ryoo et al., 1996).

Биологический контроль с использованием данных паразитов приводит к снижению количества потомства $S$. oryzae на $57 \%$. Эффективность контроля можно повысить до 90\% при помощи полировки зерна. Период развития L. differentendus на S. oryzae coставляет 20 дней при $25^{\circ} \mathrm{C}$ (Ryo et al., 1991), а для A. calandrae на S. zeamais - 17 дней (Smith, 1992). Успешность контроля зависит от нескольких факторов: полировки зерна, способствующей снижению плотности вредителя; типа зерна, который может задерживать развитие долгоносика и целостности щитка яйцекладки, участвующего в идентификации хозяина паразитом. Кроме того, паразиты демонстрируют значительное предпочтение личиночным стадиям четвертого возраста, что также косвенно влияет на идентификацию хозяина (Smith, 1993; Ryoo et al., 1996).

Smith (1994) изучал и моделировал биологический контроль S. zeamais при помощи паразитоида A. calandrae. Длительный срок жизни и длительный период яйцекладки $S$. zeamais препятствуют контролю популяции паразитоидом, однако он способен снизить темпы роста популяции долгоносика. Имитирование эффекта высвобождения различных количеств A. calandrae показало, что нет необходимости выпускать более чем в 10 раз больше паразитоидов и что соотношение $1: 1$ действительно очень эффективно. Разрыв между первым и вторым поколениями паразитоидов позволяет популяции личинок долгоносика избегать паразитизма, что приводит к последующей вспышке численности вредителя через две недели. Поэтому для эффективного контроля необходимо сводить к минимуму пробелы в паразитизме. Для высокой эффективности оптимальный временной интервал между последовательными выпусками паразитоида не должен превьшать 9 дней при $25^{\circ} \mathrm{C}$.

Throne and Lord (2004) приводят данные о биологическом контроле суринамского мукоеда $O$. surinamensis с использованием энтомопатогенного гриба B. bassiana. Применение гриба в количестве 300 мг конидий на килограмм пшеницы приводит к 72\% смертности взрослых особей (Lord, 2001). Обработка в 317 мг конидий на килограмм приводит к $91 \%$ смертности личинок и куколок (Searle and Doberski, 1984). B. bassiana эффективно обеспечивает контроль над другими вредителями, включая S. zeaтais (Adane et al., 1996), S. oryzae (Dal Bello et al., 2001, Padin et al., 2002), P. truncates (Bourassa et al., 2001, Meikle et al., 2001), A. obtectus (Ferron, 1977), R. dominica, C. ferrugineus и T. castaneum (Rice and Cogburn, 1999; Lord, 2001). Эксперименты проводили в условиях, благоприятных для O. surinamensis при $30 \pm 1{ }^{\circ} \mathrm{C}$ и $76 \%$ относительной влажности. Searle and Doberski (1984) получили $91 \%$ сокращение численности личинок и куколок в условиях температуры $20^{\circ} \mathrm{C}$ и $100 \%$ относительной влажности. Оптимальным температурным диапазоном для роста большинства изолятов B. bassiana является $25-28^{\circ} \mathrm{C}$ (Fargues et al. 1997).

Sheeba et al. (2001) тестировали B. bassiana против рисового долгоносика $S$. oryzae. Используемый в исследовании штамм, в дозировке $3.9 \cdot 10^{7}$ конидий/мл, проявляет высокую эффективность при $28 \pm 2{ }^{\circ} \mathrm{C}$ и относительной влажности $70 \pm 5 \%$, где смертность составила $76 \%$ через 25 суток, а численность потомства сократилась на $86 \%$. Эти результаты подтверждают результаты Searle and Doberski (1984), где 100\% смертность регистрировали через 20 дней после инокуляции при 100\% относительной влажности и $25^{\circ} \mathrm{C}$.

Trdan et al. (2005) исследовали эффективность четырех видов энтомопатогенных нематод S. feltiae, S. carpocapsae, H. bacteriophora, $H$. megidis для контроля над $S$. granaries. Применялась суспензия нематод в концентрациях 5000, 10000 и 20000 инфекционной молоди IJ/мл при температурах 15,20 и $25^{\circ} \mathrm{C}$ в течение недели. Наименее эффективным является H. megidis, тогда как остальные виды не имеют существенных различий в смертности. Смертность жуков достоверно повышалась при 20 и $25^{\circ} \mathrm{C}$. Влияние концентрации суспензии нематоды менее важно для биологической активности исследуемых агентов.

Суспензия $20000 \mathrm{IJ} /$ мл наиболее эффективна для контроля S. granarius (63\%). Статистически значимых различий между остальными концентрациями не выявлено, хотя они эффективны по сравнению с контрольной обработкой. Использование наивысшей концентрации (20000 IJ/мл) суспензии не оправдано, поскольку более высокие затраты на покупку биологических агентов не обеспечивают существенно более высокую эффективность по сравнению с другими двумя концентрациями. S. feltiae, S. carpocapsae и H. bacteriophora наиболее эффективны в борьбе с вредителями, поэтому все три вида могут быть рекомендованы в качестве агента биологического контроля.

Laznik et al. (2010) исследовали эффективность нескольких штаммов $S$. feltiae против $S$. oryzae. Все изученные штаммы наиболее патогенны при $25^{\circ} \mathrm{C}$ и наивысшей концентрации суспензии нематод (2 $000 \mathrm{IJ} /$ имаго), смертность составляла 42-72\%. Минимальная патогенность 6-11\% наблюдалась при низких концентрациях суспензии и температуре $30^{\circ} \mathrm{C}$. Наименьшее значение $\mathrm{LC}_{50}$ (1165 IJ/имаго) получено после 8-дневной экспозиции при $25^{\circ} \mathrm{C}$, тогда как самое высокое (2533 IJ/имаго) - при $30^{\circ} \mathrm{C}$. Слабая эффективность суспензий всех штаммов нематод при $30{ }^{\circ} \mathrm{C}$, не превышающая $20 \%$, объясняется несоответствием оптимальному интервалу температур для большинства видов энтомопатогенных нематод, который составляет $20-26{ }^{\circ} \mathrm{C}$. S. oryzae, в свою очередь, более успешно размножается при высоких температурах (25$35^{\circ} \mathrm{C}$ ). Исходя из полученных результатов, эффективность $S . f e l-$ tiae зависит от температуры и концентрации. Имеются множество работ по исследованию эффективности S. feltiae в борьбе с другими вредителями хранилищ, таких как S. granarius (Trdan et al., 2006), T. confusum (Athanassiou et al., 2007), T. molitor, T. castaneum, T. variabile, S. oryzae (Ramos-Rodriguez et al., 2006) и O. surinamensis (Svendsen and Steenberg, 2000; Schöller et al., 2006; Tóth, 2006).

Tenebrionidae. Rahman et al. (2009) исследовали влияние $X$. flavipes на нескольких видов насекомых-вредителей. X. flavipes хищник-космополит поражающий таких вредителей хранилищ как T. castaneum, T. confusum, C. pusillus, $R$. dominica и T. granarium. Arbogast (1976) сообщает, что жертвами являются 13 видов насекомых из трех отрядов. 
Эффективность $X$. flavipes зависит от размеров и плотности жертв. В пустой емкости хищник убивал малое количество крупных личинок $T$. confusum и $T$. castaneum, по сравнению с другими видами добычи и жизненными формами. Это связано с тем, что личинки могли активно избегать нападения хищника, что препятствовало их подавлению и уничтожению. Однако в пшенице данное преимущество исчезало, что значительно повышало эффективность контроля. $X$. flavipes отдает предпочтение охоте на C. pusillus, по сравнению с T. confusum и T. castaneum. Эффективность контроля зависит от пола хищника, так как самки убивают значительно больше жертв, чем самцы. Применение $X$. flavipes в программах биологического контроля вредителей зернохранилищ нуждается в проверках в производственных условиях.

Wakefield (2006) изучала прилипание и прорастание конидий B. bassiana на O. surinamensis и T. confusum. Использована концентрация $1 \cdot 10^{8}$ конидий/мл. Присоединение энтомопатогенных грибов к кутикуле насекомых является пассивным и неспецифическим (Boucias et al., 1988). Прилипание спор осуществляется посредством гидрофобных взаимодействий (Jeffs et al., 1999). Наиболее высокая смертность зарегистрирована для O. surinamensis. Для T. confusum этот показатель значительно ниже. Смертность контрольной группы составила менее $5 \%$. Высокий уровень смертности зарегистрирован для $O$. surinamensis, но для $S$. granarius обнаружены значительно более низкие уровни смертности, и они снова были ниже для T. confusum. Контрольная смертность составила менее 5\% для всех трех видов. Для каждого вида было мало различий между эффективностью двух разных изолятов B. bassiana. Количество конидий и их прорастание у $O$. surinamensis значительно выше, чем у T. confusum. Это связано с тем, что O. surinamensis имеет гораздо больше щетинок и более высокий уровень влажности на поверхности кутикулы, что обеспечивает благоприятные условия для прорастания конидий. Кутикула T. confusum предположительно содержит ингибитор для прорастания конидий. Кутикулярные углеводороды могут либо способствовать, либо ингибировать прорастание конидии (St. Leger, 1991). Кроме того, виды Tribolium производят оборонительные хиноны, которые, возможно, также могут препятствовать прорастанию.

Исследованием потенциала B. bassiana в качестве контрольного агента занимались Khashaveh et al. (2011). Эксперимент проводили на имаго T. castaneum, S. granarius и O. surinamensis, используя концентрации $0,250,500,750$ и 1000 мг/кг в течение 5,10 и 15 дней при $24 \pm 2{ }^{\circ} \mathrm{C}$ и влажности $50 \pm 5 \%$. Во всех экспериментах смертность возрастала с увеличением дозы и времени воздействия. Наивысшие показатели зарегистрированы после воздействия концентрации 1000 мг/кг в течение 15 дней и составляют $88 \%, 78 \%$ и $65 \%$ для $S$. granarius, O. surinamensis и T. castaneum соответственно. Также с повышением концентрации отмечается снижение производства потомства.

Michalaki et al. (2016) исследовали эффективность M. anisopliae для биологического контроля T. confusum. Испытывали три дозировки $8 \cdot 10^{6}, 8 \cdot 10^{8}$ и $8 \cdot 10^{10}$ конидий/кг пшеницы или муки, соответственно. Установлено, что при максимальной концентрации эффективность контроля составляет $75 \%$.

Arthur (2000) исследовал воздействие диатомовой земли на T. castaneum и T. confusum. Смертность обоих видов после первоначального воздействия была минимальной при $22^{\circ} \mathrm{C}$, но увеличивалась с повышением температуры и интервала экспозиции и снижалась при повышении относительной влажности. Максимальная смертность (100\%) для обоих насекомых наблюдалась при $32{ }^{\circ} \mathrm{C}$ и $40 \%$ относительной влажности. White and Loschiavo (1989) воздействовал на T. confusum диатомовой землей $\left(0,72 \mathrm{Mr} / \mathrm{cm}^{2}\right)$ в течение 6 ч при $25^{\circ} \mathrm{C}$ и $50 \%$ относительной влажности, что привело к абсолютной смертности через трое суток. McLaughllin (1994) экспонировал S. granarius и S. oryzae, в течение 30 ч при $25^{\circ} \mathrm{C}$ и $56 \%$ влажности в алюминиевых кастрюлях, обработанных диатомовой землей в количестве $2 \Gamma / \mathrm{m}^{2}$, и оценивал смертность в течение 6 суток. Tribolium spp. кажутся менее восприимчивыми к инертной пыли и диатомовой земле, чем другие жуки - вредители запасов (Korunic, 1998).

\section{Конкуренция в биологическом контроле}

В условиях хранилищ естественные враги насекомых-вредителей отсутствуют и единственный биотический фактор, влияющий на популяции вредителей, - конкуренция. Конкурентные взаимодействия - важный элемент биологического контроля, влияющий на целевые виды вредителей и их естественных врагов. Борьба за общие ресурсы, такие как пища и пространство, а также хищничество наблюдаются в рамках вида или между видами (Park, 1962; Park et al., 1965; Stevens and Mertz, 1985). Интродукция естественных врагов при биологическом контроле значительно влияет на конкуренцию целевых видов, что приводит к изменениям структуры сообществ. Классическими примерами изменения исхода конкуренции между двумя видами под действием паразита являются экспериментальные исследования, проведенные Park (1948) и Anderson and May (1986). В них рассматривалась конкуренция между двумя мучными хрущаками (T. confusum и $T$. castaneum) под влиянием споровика Adelina tribolii Bhatia, 1937. При отсутствии паразита в смешанной популяции наблюдается неизменное доминирование T. confusum, но при появлении паразита, доминирование исчезает. Это связано с тем, что паразит более патогенен у доминирующего конкурента и снижает конкурентоспособность $T$. confusum, позволяя сохраняться слабому T. castaneum (Hudson and Greenman, 1998).

Влияние ленточного червя Hymenolepis diminuta Rudolphi, 1819 на конкуренцию между двумя видами Tribolium исследовали Yan et al. (1998). Паразитизм цестоды оказывает отрицательное воздействие на репродуктивный успех хозяина и его конкурентоспособность (Yan, 1997). T. castaneum обычно доминирует над T. confusum, так как он более активный (Park 1948; Leslie et al., 1968). Согласно Craig (1986), при совместном обитании имаго T. castaneum преимущественно питаются более крупными яйцами T. confusum. Предсказание результатов конкуренции между двумя видами осложнено влиянием колебаний рождаемости и смертности, а также генетической изменчивостью (Park, 1948; Park et al., 1964; Dawson and Lerner, 1966; Dawson, 1970; Mertz et al., 1976, Goodnight and Craig, 1996).

T. castaneum более восприимчив к заражению H. diminuta, чем T. confusum, что повышает вероятность паразитирования (Yan and Norman, 1995). Наличие паразита приводит к снижению плодовитости самок, преобладанию в популяции самцов и учащению поедания собственных яиц взрослыми особями (Yan and Stevens, 1995). В связи с этим T. castaneum может терять конкурентоспособность перед T. confusum.

Паразитирование ленточного червя влияет на конкуренцию между двумя видами Tribolium, воздействует на смертность и плотность популяции. Наличие паразита значительно повышает конкурентоспособность $T$. castaneum, особенно при высокой начальной плотности $T$. confusum. Смертность $T$. confusum повышается при паразитировании и вид с большей вероятностью проигрывает конкуренцию. Паразитизм значительно снижает средние размеры популяции $T$. confusum и повышает среднюю плотность популяции T. castaneum в культуре двух видов. Это свидетельствует о том, что инвазия цепнем дает преимущество T. castaneum в конкурентной борьбе с T. confusum. В данной системе «паразит - хозяин конкурент» $T$. castaneum более восприимчив к ленточным червям и имеет более выраженный патогенез, чем $T$. confusum, тем самым становясь в более невыгодное положение при конкуренции. Однако индуцированные паразитом поведенческие изменения дают T. castaneum преимущество.

Alabi et al. (2008) исследовали каннибализм и хищничество среди семи видов Tribolium. Наиболее важным путем каннибализма является потребление активными формами (имаго и личинками) пассивных (яйца и куколки). Наиболее вероятен каннибализм яиц, поскольку они неподвижны, не имеют средств защиты и содержат полный набор питательных веществ в легко усваиваемой форме. Одной из высокоразвитых форм каннибализма является производство трофических яиц, цель которых - служить пищей для потомства, что является одной из форм родительской опеки 
(Crespi, 1992; Perry and Roitberg, 2006). Хотя куколки также относительно неподвижны, они более развиты, склеротизированы и могут проявлять защитную реакцию (Eisner and Eisner, 1992).

Самую высокую скорость каннибализма яиц демонстрируют личинки T. anaphe, потребляя в 10 раз больше яиц, чем личинки T. confusum и T. destructor. Среди взросльх особей T. confusum и T. brevicornis потребляли в целом 40 и более, по сравнению с T. freemani, потребляющих одно яйцо. Имаго T. brevicornis, T. confusum и T. destructor проявляют тенденцию к каннибализму яиц больше, чем их личиночные стадии, тогда как для T. anaphe, T. freemani и T. madens верно обратное. Каннибализм куколок среди личинок относительно низок, с максимумом 9 для T. anaphe. Среди имаго T. castaneum, T. confusum и T. destructor потребляли 20 или более куколок, что в 4-5 раз больше, чем их личиночные стадии, что не проявлялось у других видов. Что касается хищничества на $T$. castaneum, то T. anaphe и T. brevicornis потребляли 20 и 30 яиц, соответственно, что в 2 и 3 раза больше личинок других видов. Самыми прожорливыми среди взрослых особей были T. confusum и $T$. destructor, потребляющие 54 и 28 яиц соответственно. Куколки T. castaneum подвергались нападению преимущественно со стороны имаго, среди которых наибольшим потребителем был T. destructor, поедающий в среднем 34 куколки, тогда как другие виды потребляли менее десяти. При хищничестве на T. confusum личинки T. anaphe потребляли в среднем 47 яиц, что больше чем в два раза превышает количество потребляемых T. brevicornis и T. madens. Среди имаго T. castaneum был наиболее интенсивный поедатель как яиц, так и куколок T. confusum. Когда куколки T. brevicornis были предоставлены в качестве жертвы, они вообще не потреблялись никакими видами, и хищничество не превышало $5 \%$ для личинок и $10 \%$ для имаго.

В результате исследования идентифицировано три группы видов по каннибализму и хищничеству. Первая группа представлена T. castaneum, T. confusum и T. destructor, взрослые особи которых более прожорливы в каннибализме и хищничестве, чем их личинки. Вторая группа, в которой личинки имеют тенденцию быть более активными, чем имаго, состояла из $T$. anaphe, $T$. freemani и T. madens. Последняя группа состоит только из T. brevicornis, что вызвано высокой изменчивостью в прожорливости для разных типов добычи среди личинок и взрослых особей этого вида.

Большое значение в применении биологического контроля может иметь межвидовая конкуренция между естественными врагами определенного хозяина, так как она влияет на размер, структуру и устойчивость сообществ видов-регуляторов (Ehler, 1978; Lawton, 1986; Hagvar, 1989; van Alebeek et al., 1993; Mackauer, 1990). Межвидовая конкуренция между паразитоидами может привести к снижению уровня общего паразитирования и регулирования популяции вредителей (Turnbull and Chant, 1961; Watt, 1965; Pschorn-Walcher, 1977; Ehler and Hall, 1982). Однако возможна минимизация конкуренции между паразитоидами, путем дифференциации ниши и межвидовой специфичности к хозяину, что приведет к большему подавляющему эффекту (DeBach, 1966; Huffaker et al., 1976; Keller, 1984).

Паразитоиды из семейства Pteromalidae - A. calandrae и T. elegans атакуют незрелые стадии нескольких насекомых-вредителей зерновых. Потенциал подавления рисового долгоносика S. oryzae в пшенице этими осами продемонстрирован в ряде работ (Press et al., 1984; Cline et al., 1985; Press, 1992). Конкуренция между А. саlandrae и T. elegans исследована Wen and Brower (1995). При объединенном выпуске паразитоидов наблюдается доминирование A. calandrae, выявление которого было в три раза чаще, чем T. elegans, что совпадает с сообщениями Wen et al. (1994). Однако встречаемость как T. elegans, так и A. calandrae была значительно снижена присутствием друг друга, по сравнению с раздельными выпусками. Подавление популяций конкуренцией может быть результатом негативных взаимодействий между незрелыми стадиями или от некоторых действий имаго, влияющих на выживаемость личинок (Mackauer, 1990).

Результаты эксперимента демонстрируют наличие существенной прямой конкуренции между двумя паразитоидами, веду- щее к значительному сокращению обоих видов. Следует отметить, что подавление популяций рисового долгоносика при сочетании двух видов, имеет такой же эффект, как и при использовании только A. calandrae.

\section{Заключение}

Вредители зерна в Украине наносят значительный экономический ущерб, так как приводят к ежегодным потерям до 30\% зерна и снижают его пищевые и посевные качества. Наиболее распространенные жесткокрылые-вредители, такие как S. granarius, S. oryzae, T. confusum, $T$. castaneum, $O$. surinamensis, C. ferrugineus, A. obtectus и T. granarium, не только имеют большое значение в Украине, но и входят в списки карантинных видов основных стран-импортеров. Вредители зерновых должны уничтожаться при первом обнаружении. Современные требования к состоянию сельскохозяйственной продукции направлены на замещение химических методов борьбы на более безопасные, в том числе биологические.

Биологический контроль, по сравнению с другими методами, обладает рядом преимуществ, таких как безопасность для окружающей среды, продолжительность действия, экономичность, отсутствие остатков, простота в применении и отсутствие выработки устойчивости вредителей. В мировой практике продемонстрированы значительные экономические выгоды применения биологического контроля.

Обзор исследований эффективности различных естественных врагов основных жесткокрылых-вредителей зерновых показал, что наиболее изучены паразиты S. granarius, S. zeamais, T. confusum, T. castaneum, O. surinamensis, R. dominica, A. obtectus и C. maculatus. Естественные враги остальных видов мало изучены, а для C. latinasus, T. mauritanicus, D. lardarius, $P$. fur и B. incarnatus данные отсутствуют. Наиболее широко применяются такие естественные враги как $X$. flavipes, A. calandrae, энтомопатогенные грибы M. anisopliae и B. bassiana, а также нематоды и родов Steinerneта и Heterorhabditis. Несмотря на широкий спектр естественных врагов основных вредителей запасов, необходимы дальнейшие исследования паразитов каждого вида жесткокрылых, причиняющих экономический ущерб.

\section{References}

Adane, K., Moore, D., \& Archer, S. A. (1996). Preliminary studies on the use of Beauveria bassiana to control Sitophilus zeamais (Coleoptera: Curculionidae) in the laboratory. Journal of Stored Product Research, 32, 105-113.

Alabi, T., Michaud, J. P., Arnaud, L., \& Haubruge, E. (2008). A comparative study of cannibalism and predation in seven species of flour beetle. Ecological Entomology, 33(6), 716-726.

Al-Kirshi, A.-G. (1998). Untersuchungen zur biologischen Bekämpfung von Trogoderma granarium Everts, Trogoderma angustum (Solier) und Anthrenus verbasci L. (Coleoptera, Dermestidae) mit dem Larvalparasitoiden Laelius pedatus (Say) (Hymenoptera, Bethylidae). Humboldt-Universität zu Berlin, Dissertation.

Anderson, R. M., \& May, R. M. (1986). The invasion, persistence and spread of infectious diseases within animal and plant communities. Philosophical Transactions of the Royal Society B, 314, 533-570.

Arbogast, R. T. (1975). Population growth of Xylocoris flavipes (Hemiptera: Anthocoridae): Influence of temperature and humidity. Environmental Entomology, 4(5), 825-831.

Arbogast, R. T. (1976). Suppression of Oryzaephilus surinamensis (L.) (Coleoptera: Cucujidae) on shelled com by the predator Xylocoris flavipes (Reuter) (Hemiptera: Anthocoridae). Journal of the Georgia Entomological Society, $11,67-71$

Arbogast, R. T., \& Mullen, M. A. (1990). Interaction of maize weevil (Coleoptera: Curculionidae) and parasitoid Anisopteromalus calandrae (Hymenoptera: Pteromalidae) in small bulk of stored com. Joumal of Economic Entomology, 83(6), 2462-2468.

Arthur, F. H. (2000). Toxicity of diatomaceous earth to red flour beetles and confused flour beetles (Coleoptera: Tenebrionidae): Effects of temperature and relative humidity. Joumal of Economic Entomology, 93(2), 526-532.

Athanassiou, C. G., Kavallieratos, N. G., Menti, H., \& Karanastasi, E. (2010). Mortality of four stored product pests in stored wheat when exposed to doses 
of three entomopathogenic nematodes. Journal of Economic Entomology, 103(3), 977-984.

Athanassiou, C. G., Palyvos, N. E., \& Kakouli-Duarte, T. (2007). Insecticidal effect of Steinernema feltiae (Filipjev) (Nematoda: Steinemematidae) against Tribolium confusum du Val (Coleoptera: Tenebrionidae) and Ephestia kuehniella (Zeller) (Lepidoptera: Pyralidae) in stored wheat. Journal of Stored Products Research, 44(1), 52-57.

Athanassiou, C. G., Palyvos, N. E., \& Kakouli-Duarte, T. (2008). Insecticidal effect of Steinernema feltiae (Filipjev) (Nematoda: Steinernematidae) against Tribolium confusum du Val (Coleoptera: Tenebrionidae) and Ephestia kuehniella (Zeller) (Lepidoptera: Pyralidae) in stored wheat. Journal of Stored Products Research, 44(1), 52-57.

Awadallah, K. T., \& Afifi, A. I. (1990). The biology of the reduviid, Allaeocranum biannulipes (Mont. et Sing.), a predator of stored product insect pests. Bulletin of the Entomological Society of Egypt, 69, 169-181.

Awadallah, K. T., Tawfik, M. F. S., \& El-Husseini, M. M. (1986). Bio-cycle of the anthocorid predator Xylocoris flavipes (Reuter) in association with rearing on major pests of stored drug materials. Bulletin de la Société Entomologique d'Égypte, 66, 27-33.

Bashynska, O. (2004). The threat to grain and grain products during storage. Propozytsiia, 11, 62-66 (in Ukrainian).

Berger, H. K. (1987). Getreide gesund erhalten. Muhle + Mischfuttertechn, 10, 123-124.

Binoy, C. F. (2015). Hymenopteran parasitoids associated with some important stored product pests in Kerala, India. International Journal of Science, Environment and Technology, 4(2), 509-513.

Boucias, D. G., Pendland, J. C., \& Latge, J. P. (1988). Nonspecific factors involved in attachment of entomopathogenic deuteromycetes to host insect cuticle. Applied and Environmental Microbiology, 54, 1795-1805.

Bourassa, C., Vincent, C., Lomer, C. J., Borgemeister, C., \& Mauffette, Y. (2001). Effects of entomopathogenic Hyphomycetes against the larger grain borer, Prostephanus truncatus (Horn) (Coleoptera: Bostrichidae), and its predator, Teretriosoma nigrescens Lewis (Coleoptera: Histeridae). Journal of Invertebrate Pathology, 77(1), 75-77.

Bruce, W. A., \& LeCato, G. L. (1979). Pyemotes tritici: Potential biological control agent of stored-product insects. Recent Advances in Acarology, 213-220.

Burks, D. B. (1979). Family Pteromalidae. In: Krombein, V., Hurd, P. D., Smith, D. R., \& Burks, D. B. (Eds.). Catalog of Hymenoptera in America North of Mexico. Smithsonian Institution, Washington, DC, pp. 768-834.

Canhilal, R., \& Carner, G. R. (2006). Efficacy of entomopathogenic nematodes (Rhabditida: Steinemematidae and Heterorhabditidae) against the squash vine borer, Melittia cucurbitae (Lepidoptera: Sesiidae) in South Carolina. Journal of Agricultural and Urban Entomology, 23, 27-39.

Caroli, I., Glazer, I., \& Gaugler, R. (1996). Entomopathogenic nematode infectivity assay: Comparison of penetration rate into different hosts. Biocontrol Science and Technology, 6, 227-233.

Chatterji, S. (1955). Studies on the biology of Aplastomorpha calandrae Howard (Insecta: Hymenoptera: Chalcidae) parasitic on some storage pests. Proceedings of the Zoological Society (Calcutta), 8, 1-23.

Christensen, C. M. (1972). Microflora and seed deterioration. Viability of Seeds, 59-93.

Cline, L. D., Press, J. W., \& Flaherty, B. R. (1985). Suppression of the rice weevil, Sitophilus oryzae (Coleoptera: Curculionidae), inside and outside of burlap, woven polypropylene, and cotton bags by the parasitic wasp, Anisopteromalus calandrae (Hymenoptera: Pteromalidae). Journal of Economic Entomology, 78(4), 835-838.

Cock, M. J. W., Day, R. K., Hinz, H. L., Pollard, K. M., Thomas, S. E., Williams, F. E., Witt, A. B. R., \& Shaw, R. H. (2015). The impacts of some classical biological control successes. CAB Reviews, 10, 042.

Cock, M. J. W., Murphy, S. T., Kairo, M. T. K., Thompson, E., Murphy, R. J., \& Francis, A. W. (2016). Trends in the classical biological control of insect pests by insects: An update of the BIOCAT database. Biocontrol, 61, 349-363.

Craig, D. M. (1986). Stimuli goveming intraspecific egg predation in the flour beetles, Tribolium confusum \& T. castaneum. Researches on Population Ecology, 28, 173-183.

Crespi, B. J. (1992). Cannibalism and trophic eggs in subsocial and eusocial insects. In: Elgar, M. A., \& Crespi, B. J. (Eds.). Cannibalism: Ecology and evolution among diverse taxa. Oxford University Press, Oxford. pp. 176-213.

Dahlsten, D. L., Hansen, E. P., Zuparko, R. L., \& Norgaard, R. B. (1998). Biological control of the blue gum psyllid proves economically beneficial. California Agriculture, 52(1), 35-40.

Dal Bello, G., Padın, S., Lopez Lastra, S., \& Fabrizio, M. (2001). Laboratory evaluation of chemical-biological control of the rice weevil (Sitophilus oryzae L.) in stored grains. Journal of Stored Products Research, 37, 77-84.

Dawson, P. S., \& Lemer, I. M. (1966). The founder principle and competitive ability of Tribolium. Proceedings of the National Academy of Sciences (USA), 48, 821-826.
Dawson, P. S. (1970). A further assessment of the role of founder effects in the outcome of Tribolium competition experiments. Proceedings of the National Academy of Sciences (USA), 66, 1112-1118.

De Carvalho Barbosa Negrisoli, C. R., Negrisoli, A. S., Bernardi, D., \& Garcia, M. S. (2013). Activity of eight strains of entomopathogenic nematodes (Rhabditida: Steinernematidae, Heterorhabditidae) against five stored product pests. Experimental Parasitology, 134(3), 384-388.

DeBach, P. (1964). Biological control of insect pests and weeds. Chapman and Hall, London.

DeBach, P. (1966). The competitive displacement and coexistence principles. Annual Review of Entomology, 11, 183-212.

Dito, D. F., Shapiro-Ilan, D. I., Dunlap, C. A., Behle, R. W., \& Lewis, E. E. (2016) Enhanced biological control potential of the entomopathogenic nematode, Steinernema carpocapsae, applied with a protective gel formulation. Biocontrol Science and Technology, 26, 835-848.

Draganova, S., \& Staneva, E. (2016). Lethal effect of isolates of entomopathogenic fungi on adult insects of Trogoderma versicolor (Coleoptera: Dermestidae). Agricultural Sciences, 8(19), 25-30.

Ebrahim, A. Y. (2015). Biological control of vector bom protozoan parasites of veterinary importance. Applied Scientific Reports, 10(3), 122-127.

Ehler, L. E. (1978). Competition between two natural enemies of mediterranean black scale on olive. Environmental Entomology, 7, 521-523.

Ehler, L. E., \& Hall, R. W. (1982). Evidence for competitive exclusion of introduced natural enemies in biological control. Environmental Entomology, 11, 1-4.

EI-Orabi, M. N., Slwfei, D. M. Y., \& Amer, A. M. (2007). The interactive effect of entomopathogenic nematode, Steinernema carpocapsae (Weiser) and gamma radiation ori Callosobruchus maculatus (F.) and their biochemical Effects. Arab Journal of Nuclear Sciences and Applications, 40(3), 314-325.

Eisner, M., \& Eisner, T. (1992). Operation and defensive roles of 'gin traps' in a coccinellid pupa (Cycloneda sanguinea). Psyche a Journal of Entomology, 99, 265-274.

Fargues, J., Goettel, M. S., Smits, N., Ouedraogo, A., \& Rougier, M. (1997). Effect of temperature on vegetative growth of Beauveria bassiana isolates from different origins. Mycologia, 89, 383-392.

Fayyaz, S., \& Javed, S. (2009). Laboratory evaluation of seven Pakistani strains of entomopathogenic nematodes against a stored grain insect pest, pulse beetle Callosobruchus chinensis (L.). Journal of Nematology, 41(4), 255-260.

Ferron, P. (1977). Influence of relative humidity on the development of fungal infection caused by Beauveria bassiana (Fungi Imperfecti, Moniliales) in imagines of Acanthoscelides obtectus. BioControl, 22, 393-396.

Feydengold, V. B., Alekseeva, L. V., Zakladnoy, G. A., Lvova, A. S., \& Temirbekova, S. A. (2007). Measures to combat losses of grain during harvesting, post-harvest processing and storage at elevators and grain receiving plants. DeLi Print, Moscow (in Russian).

Flinn, P. W., \& Schöller, M. (2012). Biological control: Insect pathogens, parasitoids, and predators. In: Hagstrum, D. W., Phillips, T. W., \& Cuperus, G. (Eds.). Stored product protection. Kansas State University, Manhattan, New York. pp. 203-212.

Flinn, P. W. (1998). Temperature effects on efficacy of Choetospila elegans (Hymenoptera: Pteromalidae) to suppress Rhyzopertha dominica (Coleoptera: Bostrichidae) in stored wheat. Journal of Economic Entomology, 91, 320323.

Flinn, P. W., \& Hagstrum, D. W. (2001). Augmentative releases of parasitoid wasps in stored wheat reduces insect fragments in flour. Journal of Stored Products Research, 37, 179-186.

Flinn, P. W., Hagstrum, D. W., \& McGaughey, W. H., (1996). Suppression of beetles in stored wheat by augmentative releases of parasitic wasps. Environmental Entomology, 25, 505-511.

Flinn, P. W., Kramer, K. J., Throne, J. E., \& Morgan, T. D. (2006). Protection of stored maize from insect pests using a two-component biological control method consisting of a hymenopteran parasitoid, Theocolax elegans, and transgenic avidin maize powder. Journal of Stored Products Research, 42, 218-225.

Ganiev, M. M., Nedorezkov, V. D., \& Sharipov, H. G. (2009). Pests and diseases of grain and grain products during storage. KolosS, Moscow (in Russian).

Gonçalves, J. R., Faroni, L. R. D., Guedes, R. N. C., \& de Oliveira, C. R. F. (2004). Insecticide selectivity to the parasitic mite Acarophenax lacunatus (Cross \& Krantz) (Prostigmata: Acarophenacidae) on Rhyzopertha dominica (Fabr.) (Coleoptera: Bostrichidae). Neotropical Entomology, 33(2), 243-248.

Goodnight, C. J., \& Craig, D. M. (1996). The effect of coexistence on competitive outcome in Tribolium castaneum and T. confusum. Evolution, 50, 1241-1250.

Goswami, A., Roy, I., Sengupta, S., \& Debnath, N. (2010). Novel applications of solid and liquid formulations of nanoparticles against insect pests and pathogens. Thin Solid Films, 519, 1252-1257.

Grewal, P. S., Ehlers, R. U., \& Shapiro-Ilan, D. I. (2005). Nematodes as biocontrol agents. CABI Publishing, Cambridge, MA USA. 
Gutierrez, A. P., Caltagirone, L. E., \& Meikle, W. (1999). Evaluation of results: Economics of biological control. In: Bellows, T. S., \& Fisher, T. W. (Eds.). Handbook of biological control. Academic Press, San Diego. pp. 243-252.

Hagvar, E. B. (1989). Interspecific competition in parasitoids, with implications for biological control. Acta Entomologica Bohemoslovaca, 86, 321-335.

Haines, C. P. (1981). Laboratory studies on the role of an egg predator, Blattisocius tarsalis (Berlese) (Acari: Ascidae), in relation to the natural control of Ephestia cautella (Walker) (Lepidoptera: Pyralidae) in Warehouses. Bulletin of Entomological Research, 71(4), 557-574.

Haines, C. P. (1991). Insects and arachnids of tropical stored products: Their biology and identification (A training manual). 2nd ed. Natural Resources Institute, Chatham, UK.

Heong, K. L. (1981). Searching preference of the parasitoid, Anisopteromalus calandrae (Howard) for different stages of the host, Callosobruchus maculatus (F.) in the laboratory. Researches on Population Ecology, 23(1), 177-191.

Hill, G., \& Greathead, D. (2000). Economic evaluation in classical biological control. In: Perrings, C., Williamson, M. H. \& Dalmazzone, S. (Eds.). The economics of biological invasions. Edward Elgar, Cheltenham, 208-225.

Horshchar, O. A., Tokarchuk, G. A., \& Horshchar, V. I. (2013). The use of mixtures of preparations for the processing of grain products to protect against the most common pests. Bulletin of the Institute of Agriculture of the Steppe Zone, 7, 71-75 (in Ukrainian).

Hudson, P., \& Greenman, J. (1998). Competition mediated by parasites: Biological and theoretical progress. Trends in Ecology and Evolution, 13(10), 387-390.

Huffaker, C. G., Simmonds, F. J., \& Laing, J. E. (1976). Theoretical and empirical basis of biological control. In: Huffaker, C. B., \& Messenger, P. S. (Eds.) Theory and practice of biological control. Academic Press, New York. pp. 41-78.

Jeffs, L. B., Xavier, I. J., Matai, R. E., \& Khachatourians, G. G. (1999). Relationships between fungal spore morphologies and surface properties for entomopathogenic members of the genera Beauveria, Metarhizium, Paecilomyces, Tolypocladium and Verticillium. Canadian Journal of Microbiology, 45(11), 936-948.

Kang, Y., Wang-Shie, D., Jien-Ping, T., Chi-hu, Y., \& Wie-Chie, H. (1984). A preliminary study on the biology of the biannulated assassin bug, Peregrinator blannvlipes Montrouzier (Hemiptera, Reduviidae). Joumal of Huazhong Agricultural University, 1, 44-47.

Kavallieratos, N. G., Athanassiou, C. G., Michalaki, M. P., Batta, Y. A., Rigatos, H. A., Pashalidou, F. G., \& Vayias, B. J. (2006). Effect of the combined use of Metarhizium anisopliae (Metschinkoff) Sorokin and diatomaceous earth for the control of three stored-product beetle species. Crop Protection, 25(10), 1087-1094.

Kaya, H. K., \& Koppenhöfer, A. M. (1991). Biology and ecology of insecticidal nematodes. In: Polavarapu, S. (Ed.). Workshop proceedings: Optimal use of insecticidal nematodes in pest management. New Brunswick, NJ, United States. pp. 1-8.

Kega, V. M., Kasina, M., Olubayo, F., \& Nderitu, J. H. (2013). Management of Maliarpha separatella Rag using effective entomopathogenic nematodes and resistant rice cultivars. Journal of Economic Entomology, 10, 103-109.

Keller, M. A. (1984). Reassessing evidence for competitive exclusion of introduced natural enemies. Environmental Entomology, 13, 192-195.

Kenis, M., \& Branco, M. (2010). Chapter 5: Impact of alien terrestrial arthropods in Europe. In: Roques, A., Kenis, M., Lees, D., Lopez-Vaamonde, C., Rabitsch, W., Rasplus, J.-Y., \& Roy, D. (Eds.). Alien terrestrial arthropods of Europe. BioRisk, 4, 51-71.

Khashaveh, A., \& Chelav, H. S. (2013). Laboratory bioassay of Iranian isolates of entomopathogenic fungus Metarhizium anisopliae (Metsch.) Sorokin (Ascomycota: Hypocreales) against two species of storage pest. Agriculturae Conspectus Scientificus, 78(1), 35-40.

Khashaveh, A., Ghosta, Y., Safaralizadeh, M. H., \& Ziaee, M. (2011). The use of entomopathogenic fungus, Beauveria bassiana (Bals.) Vuill. in assays with storage grain beetles. Journal of Agricultural Science and Technology, 13, 35-43.

Khashaveh, A., Safaralizadeh, M. H., \& Ghosta, Y. (2011). Pathogenicity of Iranian isolates of Metarhizium anisopliae (Metschinkoff) (Ascomycota: Hypocreales) against Trogoderma granarium Everts (Coleoptera: Dermestidae) Biharean Biologist, 5(1), 51-55.

Khater, H. F. (2012). Ecosmart biorational insecticides: Alternative insect control strategies. In: Perveen, F. (Ed.). Insecticides - Advances in Integrated Pest Management. InTech, Rijeka, Croatia. pp. 18-61.

Klein, J. A., \& Beckage, N. E. (1990). Comparative suitability of Trogoderma variabile and T. glabrum (Coleoptera: Dermestidae) as hosts for the ectoparasite Laelius pedatus (Hymenoptera: Bethylidae). Annals of the Entomological Society of America, 83, 809-816.

Korunic, Z. (1998). Diatomaceous earths, a group of natural insecticides. Journal of Stored Products Research, 34, 87-97.

Kwenti, T. E. (2017). Biological control of parasites, natural remedies in the fight against parasites. InTech.
Lawton, J. H. (1986). The effect of parasitoids on phytophagous insect communities. In: Waage, J., \& Greathead, D. (Eds.). Insect Parasitoids. Academic Press, London.

Laznik, Z., Toth, T., Lakatos, T., Vidrih, M., \& Trdan, S. (2010). The activity of three new strains of Steinernema feltiae against adults of Sitophilus oryzae under laboratory conditions. Journal of Food, Agriculture and Environment, 8(1), 150-154.

LeCato, G. L., \& Davis, R. (1973). Preferences of the predator Xylocoris flavipes (Hemiptera: Anthocoridae) for species and instars of stored-product insects. The Florida Entomologist, 56(1), 57-59.

Leger, R. J. S. (2008). Studies on adaptations of Metarhizium anisopliae to life in the soil. Journal of Invertebrate Pathology, 96, 271-276.

Leslie, P. H., Park, T., \& Mertz, D. M. (1968). The effect of varying the initial numbers on the outcome of competition between two Tribolium species. Journal of Animal Ecology, 37, 9-23.

Lord, J. C. (2001). Desiccant dusts synergize the effect of Beauveria bassiana (Hyphomycetes: Moniliales) on stored-grain beetles. Journal of Economic Entomology, 94(2), 367-372.

Lord, J. C. (2001). Response of the wasp Cephalonomia tarsalis (Hymenoptera: Bethylidae) to Beauveria bassiana (Hyphomycetes: Moniliales) as free conidia or infection in its host, the sawtoothed grain beetle, Oryzaephilus surinamensis (Coleoptera: Silvanidae). Biological Control, 21, 300-304.

Ma, X., Wang, X., Cheng, J., Nie, X., Yu, X., Zhao, Y., \& Wang, W. (2015). Microencapsulation of Bacillus subtilis B99-2 and its biocontrol efficiency against Rhizoctonia solani in tomato. Biological Control, 90, 34-41.

Mackauer, M. (1990). Host discrimination and larval competition in solitary endoparasitoids. In: Mackauer, M., Ehler, L. E., \& Roland, J. (Eds.). Critical issues in biological control. Intercept Ltd., Andover, UK. pp. 41-62.

Mahdneshin, Z. (2011). Laboratory evaluation of the entomopathogenic fungi, Iranian isolates of Beauveria bassiana (Balsamo) Vuillemin and Metarhizium anisopliae (Metsch) Sorokin against the control of the cowpea weevil, Callosobruchus maculatus F. (Coleoptera: Bruchidae). African Journal of Microbiology Research, 5(9), 5215-5220.

McLaughlin, A. (1994). Laboratory trials on desiccant dust insecticides. In: Highley, E., Wright, E. J., Banks, H. J., \& Champ, B. R. (Eds.). Proceedings of the 6th International Conference on Stored-Product Protection. CAB Wallingsford, Canberra, Australia. pp. 638-645.

Meikle, W. G., Cherry, A. J., Holst, N., Hounna, B., \& Markham, R. H. (2001) The effects of an entomopathogenic fungus, Beauveria bassiana (Balsamo) Vuillemin (Hyphomycetes), on Prostephanus truncatus (Hom) (Col.: Bostrichidae), Sitophilus zeamais Motschulsky (Col.: Curculionidae), and grain losses in stored maize in the Benin Republic. Journal of Invertebrate Pathology, 77(3), 198-205

Menon, A., Flinn, P. W., \& Dover, B. A. (2002). Influence of temperature on the functional response of Anisopteromalus calandrae (Hymenoptera: Pteromalidae), a parasitoid of Rhyzopertha dominica (Coleoptera: Bostrichidae). Journal of Stored Products Research, 38, 463-469.

Mertz, D. B., Cawthon, D. A., \& Park, T. (1976). An experimental analysis of competitive indeterminacy in Tribolium. Proceedings of the National Academy of Sciences (USA), 73, 1368-1372.

Michalakia, M. P., Athanassioua, C. G., Kavallieratosb, N. G., Battac, Y. A., \& Balotisd, G. N. (2006). Effectiveness of Metarhizium anisopliae (Metschnikoff) Sorokin applied alone or in combination with diatomaceous earth against Tribolium confusum Du Val larvae: Influence of temperature, relative humidity and type of commodity. Crop Protection, 25(5), 418-425.

Murata, M., Imamura, T., \& Miyanoshita, A. (2016). Suppression of the storedproduct pest Sitophilus zeamais (Coleoptera: Curculionidae) by simultaneous release of a predatory bug and a parasitoid wasp. Biocontrol Science and Technology, 26(6), 872-876.

Mwaitulo, S., Haukeland, S., Sñthre, M. G., Laudisoit, A., \& Maerere, A. P. (2011). First report of entomopathogenic nematodes from Tanzania and their virulence against larvae and adults of the banana weevil Cosmopolites sordidus (Coleoptera: Curculionidae). Intemational Journal of Tropical Insect, 31, 154-161.

Nishi, A., \& Takahashi, K. (2002). Effects of temperature on oviposition and development of Amphibolus venator (Klug) (Hemiptera: Reduviidae), a predator of stored product insects. Applied Entomology and Zoology, 37(3), 415-418.

Nishi, A., Imamura, T., Miyanoshita, A., Morimoto, S., Takahashi, K., Visarathanonth, P., Kengkanpanich, R., Shazali, M. E. H., \& Sato, K. (2004). Predatory abilities of Amphibolus venator (Klug) (Hemiptera: Reduviidae), a predator of stored-product insect pests. Applied Entomology and Zoology, 39(2), 321-326.

Noosidum, A., Satwong, P., Chandrapatya, A., \& Lewis, E. E. (2016). Efficacy of Steinernema spp. plus anti-desiccants to control two serious foliage pests of vegetable crops, Spodoptera litura F. and Plutella xylostella L. Biological Control, 97, 48-56. 
Oliveira, C. R. F., Faroni, L. R. D’A., Guedes, R. N. C., \& Pallini, A. (2003). Parasitism by the mite Acarophenax lacunatus on beetle pests of stored products. BioControl, 48(5), 503-513.

Padin, S., Dal Bello, G., \& Fabrizio, M. (2002). Grain loss caused by Tribolium castaneum, Sitophilus oryzae and Acanthoscelides obtectus in stored durum wheat and beans treated with Beauveria bassiana. Journal of Stored Products Research, 38, 69-74.

Park, T. (1948). Experimental studies of interspecies competition. I. Competition between populations of flour beetles, Tribolium confusum Duval and Tribolium castaneum Herbst. Ecological Monographs, 18, 265-308.

Park, T. (1962). Beetles, competition and populations. Science, 138, 1369-1375.

Park, T., Leslie, P. H., \& Mertz, D. B. (1964). Genetic strains and competition in populations of Tribolium. Physiological Zoology, 37, 97-162.

Park, T., Mertz, D. B., Grodzinski, W., \& Prus, T. (1965). Cannibalistic predation in populations of flour beetles. Physiological Zoology, 38, 289-321.

Perry, J. C., \& Roitberg, B. D. (2006). Trophic egg laying: Hypotheses and tests. Oikos, 112, 706-714

Pingale, S. V. (1954). Biological control of some stored grain pests by the use of a bug predator, Amphibolus venator Klug. Indian Journal of Entomology, 16, 300-302.

Pöschko, M., Laborius, G.-A., \& Schulz, F. A. (1992). Ability of Teretriosoma nigrescens to survive and breed on stored product pests other than Prostephanus truncatus. Proc. FAO/GTZ coordinating meeting, implementation of and further research biological control of the larger grain borer, Lomé, Togo. pp. 85-95.

Press, J. W. (1992). Comparative penetration efficacy in wheat between the weevil parasitoids Anisopteromalus calandrae and Choetospila elegans (Hymenoptera: Pteromalidae). Journal of Entomological Science, 27, 154-157.

Press, J. W., Cline, L. D., \& Flaherty, B. R. (1984). Suppression of residual populations of the rice weevil, Sitophilus oryzae, by the parasitic wasp, Anisopteromalus calandrae. Journal of the Georgia Entomological Society, 19, 110-113.

Pschorn-Walcher, H. (1977). Biological control of forest insects. Annual Review of Entomology, 22, 1-22.

Quesada-Moraga, E., Ruiz-Garcia, A., \& Santiago-Alvarez, C. (2006). Laboratory evaluation of entomopathogenic fungi Beauveria bassiana and Metarhizium anisopliae against puparia and adults of Ceratitis capitata (Diptera: Tephritidae). Journal of Economic Entomology, 99, 1955-1966.

Rahiminejad, V., \& Hajiqanbar, H. (2015). A new species of the genus Acarophenax (Acari: Heterostigmatina: Acarophenacidae) associated with Sphindus sp. (Coleoptera: Sphindidae) from Iran. Persian Journal of Acarology, 4(3), 277-286.

Rahman, M. M., Islam, W., \& Ahmed, K. N. (2009). Functional response of the predator Xylocoris flavipes to three stored product insect pests. International Journal of Agriculture and Biology, 11(3), 316-320.

Ramos-Rodriguez, O., Campbell, J. F., \& Ramaswamy, S. B. (2006) Pathogenicity of three species of entomopathogenic nematodes to some major stored-product insect pests. Journal of Stored Products Research, 42, 241-252.

Reichmuth, C. (2000). Biological control in stored product protection. Integrated Protection of Stored Products IOBC Bulletin, 23(10), 11-23.

Rice, W. C., \& Cogburn, R. R. (1999). Activity of the entomopathogenic fungus Beauveria bassiana (Deuteromycota: Hyphomycetes) against three coleopteran pests of stored grain. Journal of Economic Entomology, 92, 691-694.

Richter, J., Biliwa, A., Helbig, J., Fischer, H. U., \& Henning-Helbig, S. (1997). Impact of Teretriosoma nigrescens Lewis (Col., Histeridae) on Prostephanus truncatus (Horn) (Col., Bostrichidae) and losses in traditional maize in southem Togo. Journal of Stored Products Research, 33(2), 137-142.

Riudavets, J., \& Lucas, É. (2000). Biological control of Sitophilus oryzae (Coleoptera: Curculionidae) in rice and combined effects with a polishing process. Integrated Protection of Stored Products IOBC Bulletin, 23(10), 143-148.

Riudavets, J., Maya, M., \& Monserrat, M. (2002). Predation by Blattisocius tarsalis (Acari: Ascidae) on stored product pests. Integrated Protection of Stored Products IOBC Bulletin, 25(3), 121-126.

Romero Ferreira de Oliveira, C., de Sousa, A. H., Guerra Pimentel, M. A., Cysneiros Matos, C. H., \& D’Antonino Faroni, L. R. (2010). First record for Cathartus quadricollis and Callosobruchus maculatus cultures attacked by the mite Pyemotes tritici. Idesia (Arica), 28(3), 97-100.

Roy, H. E., Brown, P. M. J., Adriaens, T., Berkvens, N., Borges, I., ClusellaTrullas, S., De Clercq, P., Comont, R. F., Eschen, R., Estoup, A., Evans, E. W., Facon, B., Gardiner, M. M., Gil, A., Grez, A. A., Guillemaud, T., Haelewaters, D., Herz, A., Honek, A., Howe, A. G., Hui, C., Hutchison, W. D., Kenis, M., Koch, R. L., Kulfan, J., Lawson Handley, L., Lombaert, E., Loomans, A., Losey, J., Lukashuk, A. O., Maes, D., Magro, A., Murray, K. M., San Martin, G., Martinkova, Z., Minnaar, I. A., Nedved, O., OrlovaBienkowskaja, M. J., Rabitsch, W., Ravn, H. P., Rondoni, G., Rorke, S. L., Ryndevich, S. K., Saethre, M.-G., Sloggett, J. J., Soares, A. O., Stals, R. Tinsley, M. C., Vandereycken, A., van Wielink, P., Viglasova, S., Zach, P.,
Zakharov, I. A., Zaviezo, T., \& Zhao, Z. (2016). The harlequin ladybird, Harmonia axyridis: Global perspectives on invasion history and ecology. Biological Invasions, 18, 997-1044.

Rumbos, C. I., \& Athanassiou, C. G. (2012). Insecticidal effect of six entomopathogenic nematode strains against Lasioderma serricorne (F.) (Coleoptera: Anobiidae) and Tribolium confusum Jacquelin du Val (Coleoptera: Tenebrionidae). Joumal of Stored Products Research, 50, 21-26.

Russo, A., Cocuzza, G. E., \& Vasta, M. C. (2004). Life tables of Xylocoris flavipes (Hemiptera: Anthocoridae) feeding on Tribolium castaneum (Coleoptera: Tenebrionidae). Journal of Stored Products Research, 40(1), 103-112.

Ryoo, M. I., Hong, Y. S., \& Yoo, C. K. (1991). Relationship between temperature and development of Lariophagus distinguendus (Hymenoptera: Pteromalidae), an ectoparasitoid of Sitophilus oryzae (Coleoptera: Curculionidae). Journal of Economic Entomology, 84, 825-829.

Ryoo, M. I., Yoon, T. J., \& Shin, S. S. (1996). Intra- and interspecific competition among two parasitoids of the rice weevil (Coleoptera: Curculionidae). Environmental Entomology, 25(5), 1101-1108.

Salt, G. (1938). Experimental studies in insect parasitism. VI. - Host suitability george salt. Bulletin of Entomological Research, 29(3), 223-246.

Schmale, I., Wäckers, F. L., Cardona, C., \& Dorn, S. (2001). Control potential of three hymenopteran parasitoid species against the bean weevil in stored beans: The effect of adult parasitoid. Biological Control, 21, 134-139.

Schöller, M., Flinn, P. W., Grieshop, M. J., \& Žd’árková, E. (2006). Biological control of stored product pests. In: Heaps, J. (Ed.). Insect management for food storage and processing. 2nd Edn. American Association of Cereal Chemists. pp. 67-87.

Schroer, S., Ziermann, D., \& Ehlers, R. U. (2005). Mode of action of a surfactant polymer formulation to support performance of the entomopathogenic nematode Steinernema carpocapsae for control of diamondback moth larvae (Plutella xylostella). Biocontrol Science and Technology, 15, 601-613.

Searle, T., \& Doberski, J. (1984). An investigation of the entomogenous fungus Beauveria bassiana (Bais.) Vuill. as a potential biological control agent for Oryzaephilus surinamensis (L.). Journal of Stored Products Research, 20, 17-24.

Serednyak, D. P., \& Fedorenko, V. P. (2014). Phosphine fumigation against pests of grain stocks. Plant Protection and Quarantine, 60, 293-302 (in Russian).

Shafighi, Y., Ziaee, M., \& Ghosta, Y. (2014). Diatomaceous earth used against insect pests, applied alone or in combination with Metarhizium anisopliae and Beauveria bassiana. Journal of Plant Protection Research, 54(1), 62-66.

Shah, F. A., Wang, C. S., \& Butt, T. M. (2005). Nutrition influences growth and virulence of the insect-pathogenic fungus Metarhizium anisopliae. FEMS Microbiology Letters, 251(2), 259-266.

Sheeba, G., Seshadri, S., Raja, N., Janarthanan, S., \& Ignacimuthu, S. (2001). Efficacy of Beauveria bassiana for control of the rice weevil Sitophilus oryzae (L.) (Coleoptera: Curculionidae). Applied Entomology and Zoology, 36(1), 117-120.

Shrestha, S., \& Kim, Y. (2010). Differential pathogenicity of two entomopathogenic bacteria, Photorhabdus temperata subsp. temperata and Xenorhabdus nematophila against the red flour beetle, Tribolium castaneum. Journal of Asia-Pacific Entomology, 13(3), 209-213.

Smith, L. (1992). Effect of temperature on life history characteristics of Anisopteromalus calandrae (Hymenoptera: Pteromalidae) parasitizing maize weevil larvae in corn kemels. Environmental Entomology, 21(4), 877-887.

Smith, L. (1993). Host-size preference of the parasitoid Anisopteromalus calandrae (Hymenoptera: Pteromalidae) on Sitophilus zeamais (Coleoptera: Curculionidae) larvae with a uniform age distribution. BioControl, 38(2), 225-233.

Smith, L. (1994). Computer simulation model for biological control of maize weevil by the parasitoid Anisopteromalus calandrae. In: Highley, E., Wright, E. J., Banks, H. J., \& Champ, B. R. (Eds.). Stored product protection, Proceedings of the 6th International Working Conference on stored-product protection, 17-23 April 1994, Canberra, Australia. CAB International, Wallingford, United Kingdom. pp. 1147-1151.

Sokolov, E. A. (2004). Pests of stocks, their quarantine value and control measures. Printing House "Dimur", Orenburg. (in Russian).

St. Leger, R. J. (1991). Integument as a barrier to microbial infections. In: Binnington, K., \& Retnakaran, A. (Eds). Physiology of the insect epidermis, CSIRO Publishing, Clayton, Australia. pp. 284-306.

Stevens, L., \& Mertz, D. B. (1985). Genetic stability of cannibalism in Tribolium confusum. Behavior Genetics, 15, 549-559.

Svendsen, T. S., \& Steenberg, T. (2000). The potential use of entomopathogenic nematodes against Typhaea stercorea. Biocontrol, 45, 97-111.

Tawfik, M. F. S., Awadallah, K. T., \& Abou-Zeid, N. A. (1983). The biology of the reduvid Allaeocranum biannulipes (Montr. et Sign.), a predator of storedproduct insects. Bulletin of the Entomological Society of Egypt, 64, 231-238.

Throne, J. E., \& Lord, J. C. (2014). Control of sawtoothed grain beetles (Coleoptera: Silvanidae) in stored oats by using an entomopathogenic fungus in conjunction with seed resistance. Journal of Economic Entomology, 97(5), 1765-1771. 
Tóth, T. (2006). Collection of entomopathogenic nematodes for the biological control of insect pests. Journal of Plant Research, 14, 225-230.

Trdan, S., Valic, N., Urek, G., \& Milevoj, L. (2005). Concentration of suspension and temperature as factors of pathogenicity of entomopathogenic nematodes for the control of granary weevil, Sitophilus granarius (L.) (Coleoptera: Curculionidae). Acta Agriculturae Slovenica, 85(1), 117-124.

Trdan, S., Vidrih, M., \& Valič, N. (2006). Activity of four entomopathogenic nematode species against young adults of Sitophilus granarius (Coleoptera: Curculionidae) and Oryzaephilus surinamensis (Coleoptera: Silvanidae) under laboratory conditions. Journal of Plant Diseases and Protection, 113, 168-173.

Turnbull, A. L., \& Chant, D. A. (1961). The practice and theory of biological control of insects in Canada. Canadian Journal of Zoology, 39, 697-753.

Upadhyay, R. K., \& Ahmad, S. (2011). Management strategies for control of stored grain insect pests in farmer stores and public ware houses. Ahmad World Journal of Agricultural Sciences, 7(5), 527-549.

Van Alebeek, F. A. N., Rojas-Rousse, D., \& Leveque, L. (1993). Interspecific competition between Eupelmus vuilleti and Dinarmus basalis, two solitary ectoparasitoids of Bruchidae larvae and pupae. Entomologia Experimentalis et Applicata, 69, 21-31.

Wakefield, M. E. (2006). Factors affecting storage insect susceptibility to the entomopathogenic fungus Beauveria bassiana. 9th International working conference on product protection, October 15-18, Compinas, Sao Paulo, Brazil. pp. 855-862.

Watt, K. E. F. (1965). Community stability and the strategy of biological control. The Canadian Entomologist, 97, 887-895.
Wen, B., Smith, L., \& Brower, J. H. (1994). Competition between Anisopteromalus calandrae and Chetospila elegans (Hymenoptera: Pteromalidae) at different parasitoid densities on immature maize weevil (Coleoptera: Curculionidae) in com. Environmental Entomology, 23(2), 367-373.

White, N. D. G., \& Loschiavo, S. R. (1989). Factors affecting survival of the merchant grain beetle (Coleoptera: Cucujidae) and the confused four beetle (Coleoptera: Tenebrionidae) exposed to silica aerogel. Journal of Economic Entomology, 82, 960-969.

Williams, R. N., \& Floyd, E. H. (1971). Effect of two parasitoids, Anisopteromalus calandrae and Chaetospila elegans upon populations of the maize weevil under laboratory and natural conditions. Journal of Economic Entomology, 64, 1407-1408.

Yan, G. (1997). Fitness consequences of larval tapeworm infection for its intermediate host, Tribolium beetle. Canadian Journal of Zoology, 75, 271-279.

Yan, G., \& Norman, S. (1995). Infection of Tribolium beetles with a tapeworm: Variation in susceptibility within and between beetle species and among genetic strains. Joumal of Parasitology, 81, 37-42.

Yan, G., \& Stevens, L. (1995). Selection by parasites on components of fitness in Tribolium beetles: The effect of intraspecific competition. American Naturalist, 146, 795-813.

Yan, G., Stevens, L., Goodnight, C. J., \& Schall, J. J. (1998). Effects of a tapeworm parasite on the competition of Tribolium beetles. Ecology, 79(3), 1093-1103.

Zakladnoi, G. A. (2006). Pests of grain stocks. Plant Protection and Quarantine, 6, 24 (in Russian). 